Copyright

by

Hye Jin Bang

2013 
The Thesis Committee for Hye Jin Bang Certifies that this is the approved version of the following thesis:

Consumer Response to Ads in Social Network Sites: An Exploration into the Role of Ad Location and Path

\begin{abstract}
APPROVED BY SUPER VISING COMMITTEE:
\end{abstract}

Supervisor:

Wei-Na Lee

Gary Wilcox 
Consumer Response to Ads in Social Network Sites: An Exploration into the Role of Ad Location and Path

\author{
by \\ Hye Jin Bang, B.Comm. \\ Thesis \\ Presented to the Faculty of the Graduate School of \\ The University of Texas at Austin \\ in Partial Fulfillment \\ of the Requirements \\ for the Degree of \\ Master of Arts
}

The University of Texas at Austin

May 2013 


\section{Dedication}

I dedicate my masters' thesis to my parents and sister who support and believe in me. 


\section{Acknowledgements}

I would like to express my deepest gratitude to my advisor, Dr. Wei-Na Lee. Her endless encouragement and guidance from the initial to the final level enabled me to gradually develop my masters' thesis. Without her strong support, I would have not completed my thesis. I also express my appreciation to Dr. Gary B. Wilcox for his encouragement and comments. 


\title{
Abstract \\ Consumer Response to Ads in Social Network Sites: An Exploration into the Role of Ad Location and Path
}

\author{
Hye Jin Bang, MA \\ The University of Texas at Austin, 2013
}

Supervisor: Wei-Na Lee

Past research repeatedly suggests consumer's defensive response to persuasive attempts is a key challenge for advertisers. Given the explosive growth of social media, this study aims to understand if consumer response to ads placed in a social network site could be influenced by ad location and the path through which the ad is delivered. Findings from an experiment suggest that consumers' attention to ads in SNSs is remarkably low. Furthermore, the interaction between ad location and the path significantly influences consumers' attitudes toward the ad, attitudes toward the brand, and purchase intention. Specifically, it appears that an ad placed inside users' timeline and sent through via known others, the indirect path, yielded favorable consumer response. On the other hand, consumers responded more favorably to an ad sent by the advertiser, the direct path, than that sent by known others if the ad is placed outside users' timeline. Implications and suggestions for future research are provided. 


\section{Table of Contents}

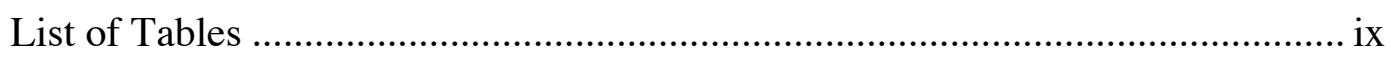

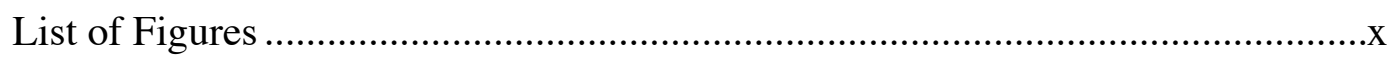

Chapter 1 Introduction ..............................................................................

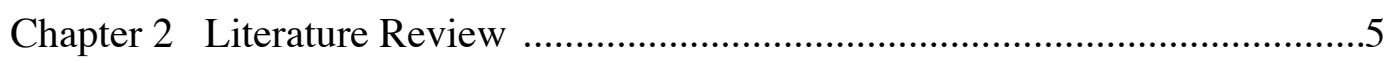

Advertising Avoidance in Traditional Media .................................................5

Consumers' low attention to Online Advertising ...........................................

Advertising in Social Networking Sites ......................................................13

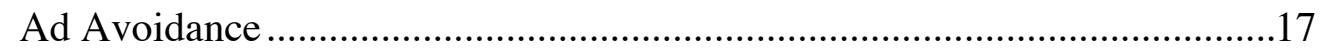

Persuasion Knowledge Model ...........................................................18

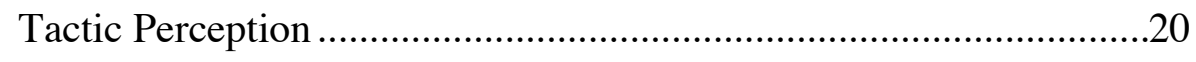

Advertising Location in SNSs ....................................................................22

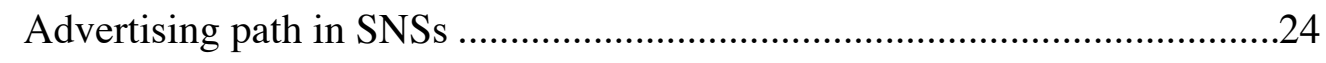

Chapter 3 Framework and Research Hypotheses ……………………..............31

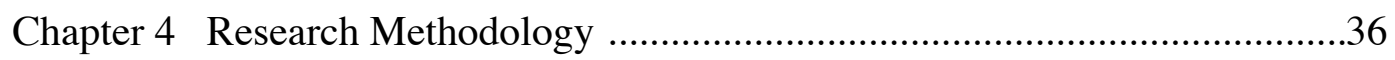

Overview and Research Design .....................................................................

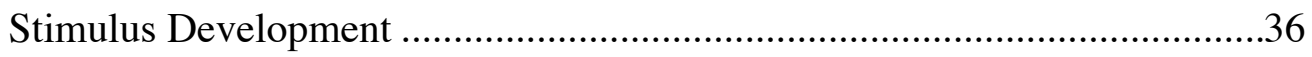

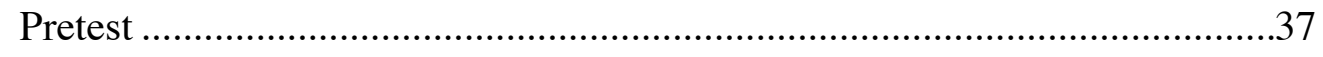

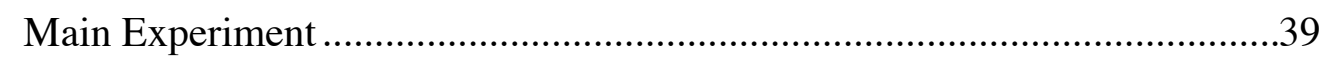

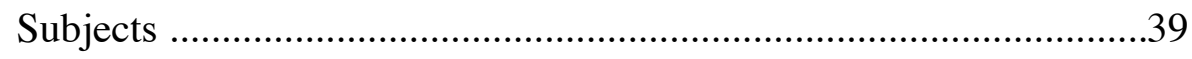

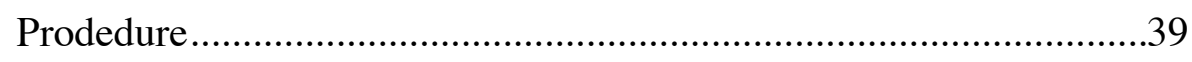

Independent Variables and Manipulation.......................................................40

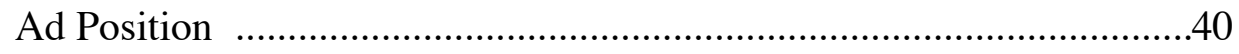




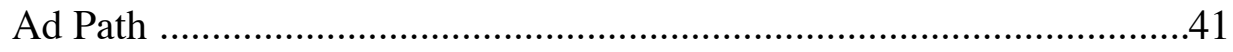

Dependent Variables and Measurement ..................................................4

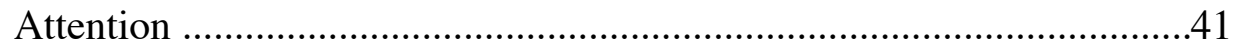

Advertising Effectiveness (Aab, Ab, PI) ........................................42

Additional Measure ..................................................................42

Chapter 5 Data Analysis and Results ...................................................43

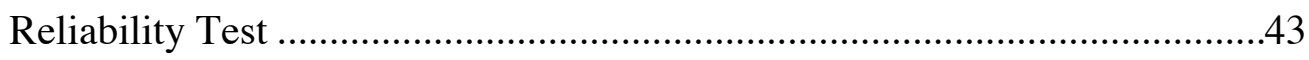

Manipulation Check ......................................................................4

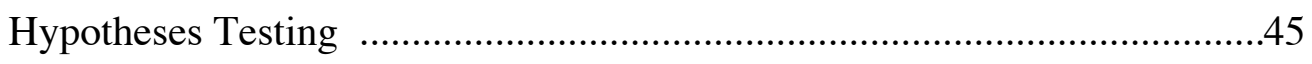

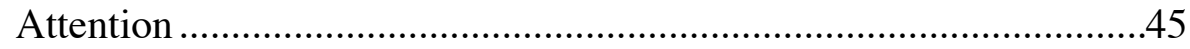

Advertising Evaluation ........................................................46

Chapter 6 Discussion and Conclusion …........................................................52

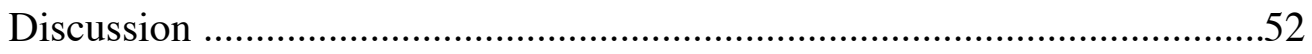

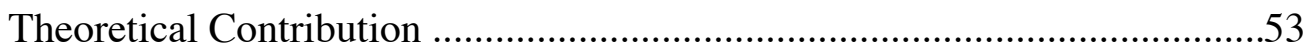

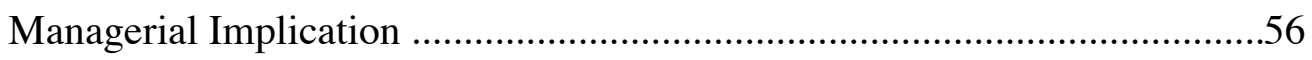

Limitation and Future Research ............................................................57

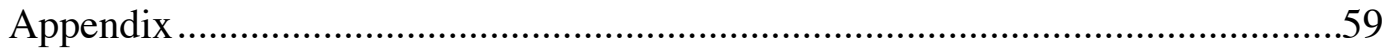

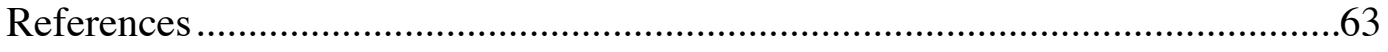




\section{List of Tables}

Table 2.1: Formats of Online Advertising .....................................................13

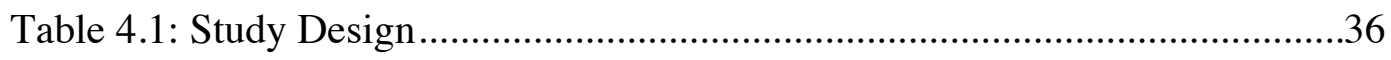

Table 5.1: Reliability Analysis of Measurement Items .................................42

Table 5.2: Manipulation Check Questions.......................................................44

Table 5.3: Univariate Analysis of Variance Results ..........................................49

Table 5.4: Cell Means and Sample Sizes .............................................................49 


\section{List of Figures}

Figure 2.1 Examples of Direct and Inside SNS ad (left) and Direct and Outside ad

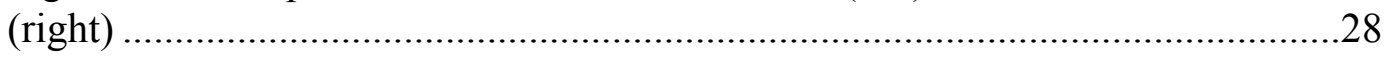

Figure 2.2: Examples of Indirect and Inside SNS ad .....................................29

Figure 2.3: Examples of Indirect and Outside SNS ad ......................................30

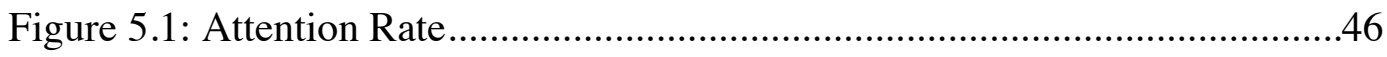

Figure 5.2: Mean Attitude toward the advertisement by ad location and ad path .50

Figure 5.3: Mean Attitude toward the brand by ad location and ad path...............50

Figure 5.4: Mean Purchase Intention by ad location and ad path ........................51 


\section{CHAPTER 1. INTRODUCTION}

Kaplan and Haenlein (2010) defined SNSs as "a group of Internet-based

applications that build on the ideological and technological foundations of Web 2.0, and that allow the creation and exchange of User Generated Content" (p. 61). By 2012, the number of SNSs users exceeded 1.4 billion (eMarketer, 2012). SNSs had become a promising platform for advertising, where 2012 expenditures exceeded $\$ 7$ billion dollars (eMarketer, 2012). Approximately half that came in the US market.

The question is did such spending produce the desired results. General Motors (GM), the third-largest advertiser in the United States discontinued paid advertising on Facebook on March15, 2012 (CNN Money 2012). According to a GM official, although they spent $\$ 10$ million on Facebook ads in 2011, there had been little impact on their consumers (The Wall Street Journal 2012). GM's action highlights advertisers' concern about the effectiveness of advertising on social networking sites (SNSs). The low level of click-through-rate (CTR) on SNS ads has continually been pointed out (Webtrends 2011), and the example above marks the first major incident of advertisers acting on their doubts over the effectiveness of advertising on SNSs. According to several studies conducted by the industry, consumers overall are less likely to be aware of SNS ads, and more likely to perceive them as annoying (IDC, 2008). It also calls for a better understanding of the mechanism behind consumers' responses toward SNS ads.

Regarding the mechanism, this research puts forward in Chapter 2 the persuasion knowledge model (Friestand and Wright 1994). This model demonstrates the process of people coping with purposive tactics, such as advertising. According to Friestand and 
Wright (1994), the concept of "tactic perception" is significant in activating consumers' persuasion knowledge. That is, if consumers recognize something as a "purposive tactic (e.g., advertising)," they automatically generate, based on their persuasion knowledge, a defensive coping behavior (e.g., reduced attention). In fact, researchers have discovered as a consequence of persuasion knowledge activation significantly reduced attention and negative responses toward advertising (Goodstein 1993; James and Kover 1992; Campbell and Kirmani 2000). More interestingly, as consumers become familiar with certain types of marketing tactics, their responses become more automatic and effortless (Friestand and Wright 1994).

There are some factors that might influence consumers' response to persuasive messages in SNSs. Factors such as relevance of product, skepticism about advertising messages, skepticism about SNSs as an advertising medium and previous negative experience, have all been suggested (Kelly at al. 2010). However, since Kelly at al' (2010) study is one of the limited research on consumers' responses to ads in SNSs, further research is needed to investigate what determine consumers' responses to SNS ads. Wilkonson et al. (1995) argue that executional factors could determine consumers' tactic perception of ads. Specifically, Wilkonson et al. (1995) suggest that factors, such as presence of sponsor and appearance characteristics (e.g., layout, could facilitate consumers' ad identification. Further, as one of the important executional factors affecting consumers' responses to ads, ad location have been discussed in online advertising literature (Kim et al. 1997; Nielson 2000; Agarwal, Hosanagar, and Smith 20 11). Therefore, as one of the first attempts to examine the influence of executional factors 
in SNS environment, this research would discuss the location of ad and the path through which the ad is delivered.

Chapter 2 introduces the two unique characteristics of SNSs ads—ad location and ad path — as variables that trigger tactic perception in SNS environments. In online advertising literature, a great deal of research has examined the impact of different ad locations on consumers' responses toward online advertising (Kim et al., 1997; Calisir and Karaali 2009; Lin and Chen, 2009). Interestingly, advertisers have two ad placement options in most SNSs (e.g., Facebook, Twitter and etc.), either inside users' personal timeline or outside it. However, no studies have examined the impact these two options have on consumers' responses towards SNS ads. Further, most of the relationships people have on SNSs is based on their' real-life human network. Hence, information sent by an unknown other (an advertiser say) might be easily identified and considered to be not credible (Chu and Kim, 2011). This research assumes that the interaction of ad location and ad path on SNSs will vary the level of tactic perception, which ultimately influences consumers' responses to SNS ads.

It has been pointed out that most online advertising research has focused on what occurs after users have paid attention to the ad (Duff and Faber 2011). In other words, most research has assumed that online advertisements are attended to by consumers. However, inattention or ad avoidance is a prevailing phenomenon in the web environment. Since online advertisements coexist with other content and share bandwidth (Dreze and Hussherr 2003), and consumers tend to be more goal-directed in the Internet environment (Cho and Cheon 2004; Li, Edwards and Lee 2002), attention grabbing on 
the Internet is much harder to achieve than in any other medium. That is, ad avoidance in the online environment is much easier to do than in any other media environment (Dreze and Hussherr 2003). This pattern of consumer response towards advertising is predominant in the SNS environment (IDC, 2008). Hence, in the online environment, the task of attracting attention is much more challenging than ever before. Even more daunting is the follow-up task of generating favorable responses towards attended ads. Therefore, it is important to understand the nature of consumer attention prior to examining consumers' responses to SNS ads. Given these, this research is an initial attempt to examines factors that facilitate or hamper consumers' attendance to SNS ads and their subsequent responses.

The remainder of current study is structured as follows: Chapter 2 presents the literature review and illustrates fundamental theoretical constructs as indicated above. Chapter 3 develops the hypotheses of the study. Chapter 4 explains the research methodology with a description of the procedure. The results of the empirical investigation are offered in Chapter 5. Chapter 6 discusses the theoretical and managerial contributions and points out the limitations of the current study and offers suggestions for future research. 


\section{CHAPTER 2: LITERATURE REVIEW}

\section{ADVERTISING AVOIDANCE IN TRADITIONAL MEDIA}

Ever since the 1980s, when the amount of advertising increased significantly, the phenomenon of advertising avoidance became a major concern for advertisers. This topic attracted attention from academic researchers and practitioners (Zanot 1984). Beyond the discussion about cognitive avoidance (e.g., lack of attendance), the technological developments of remote control and VCR further contributed to research on the behavioral aspect of advertising avoidance via devices (Lerner 1988). This interest resulted in a great deal of research on the extent and pattern of advertising avoidance in a traditional media environment from 1980 to 1990 (Heeter and Greenberg 1985; Speck and Elliot 1997)

Speck and Elliot (1997) defined advertising avoidance as "all actions by media users that differentially reduce their exposure to advertising contents" (p. 61). According to them, advertising avoidance may be classified into three types: cognitive, behavioral and mechanical. Cognitive avoidance refers to an audience's intentional removal of attention from advertising. In other words, audience ignores advertising. Behavioral avoidance refers to a media user's behavioral action to avoid advertising, such as leaving the room. Finally, mechanical avoidance refers to avoidance assisted by mechanical devices such as switching channels with a remote control. Fundamentally, mechanical avoidance may be viewed as a form of behavioral avoidance aided by the use of a mechanical device.

A large part of earlier advertising avoidance research focused specifically on 
television since advertising avoidance occurs more with TV than with other media such as radio, newspapers and magazines (Heeter and Cohen 1988; Speck and Elliot 1997). Given this, Heeter and Greenberg (1985) profiled people who avoided TV commercials by "zapping" them. Zapping refers to "a situation in which channel switching occurs during commercial" (p.125). Zipping, a related advertising avoidance phenomenon, refers to "fast-forwarding by viewers through commercials when playing a pre-recorded or rented videotape" (Cronin and Menelly 1992, p.1). They found that young and affluent males were more likely to zap TV commercials. Furthermore, several studies have examined the impact of media-related variables such as the breadth of media consumption and attitude towards media on advertising avoidance. For example, researchers observed that people who chose many television stations were more likely to avoid commercials than people who watched few (Abernethy 1991; Heeter and Cohen 1988). Results on the effects of such advertising avoidance, however, are somewhat mixed. Some researchers (Greene 1988; Zufryden et al. 1993) have argued that zapped ads are more effective than non-zapped ads since viewers' eyes must be on the screen at the time of zapping. Other researchers (Speck and Elliot 1997; Alan and Ruby 2001) have contended the opposite, arguing that zapping behavior has a negative impact on advertising recall.

Meanwhile, researchers have studied the impact of attitudes towards advertising on TV advertising avoidance (Siddarth and Chattopadhyay 1998; Cronin and Menelly 1992). Siddarth and Chattopadhyay (1998) found that the amount of advertising avoidance could significantly decrease if commercials contained brand-differentiating 
messages. This is because such information is perceived to be more useful and valuable by allowing consumers to make a distinction among brands. A brand-differentiating message not only generates positive attitude toward advertising, but also enhances message recall and comprehension (Stewart and Furse 1986). Similarly, Speck and Elliot (1997) also pointed out that unbelievable or annoying commercials contribute to viewers' avoidance behavior. These findings all seem rather intuitive. However, other researchers have argued that the content of advertising may have no impact on advertising avoidance. Cronin and Menelly (1992) suggested that avoidance is due largely to the presence of advertising, not because of what is perceived to be in those commercials. In other words, people avoid TV commercials without even processing the information that is given in the content.

In other types of media, however, research on advertising avoidance is somewhat limited. Heeter and Cohen (1988) conducted research to identify a pattern of advertising avoidance in radio. Heeter and Cohen (1988) found that people switched radio channels more during commercial breaks rather than during the programs. Furthermore, advertising avoidance in radio was more prevalent when people were in their cars than at home. Heeter and Cohen (1988) also found that younger and lower income listeners were more likely to zap radio commercials. In addition, Speck and Elliot (1997) found that age, breadth of search, and disruption are the strongest predictors for advertising avoidance in radio. More specifically, if listeners are young, unmarried and if they sample many radio stations, they are more likely to avoid radio commercials. Commercials that are perceived to hinder a search for programming or to be disruptive are more likely to be 
skipped as well.

During the 1970s and 1980s, research on advertising avoidance in magazines and newspapers was primarily conducted by the ad industry rather than academia. The focus at that time was to provide descriptive information on the relationship between demographic factors and advertising avoidance in print media. According to Magazine Publishers of America (1979), women viewed more advertisements in magazines than did men. Further, more affluent and older readers were more likely to skip or avoid ads in magazines and newspapers (Newspaper Advertising Bureau 1973; Magazine publishers of America 1991). According to the research conducted by Speck and Elliot (1997), advertising avoidance in magazines is the second highest after television among the four major media (television, radio, magazine and newspaper). Similar to industry research, Speck and Elliot (1997) identified important demographic predictors of advertising avoidance in print media as being age and income. In addition, Speck and Elliot (1997) found that the two strongest predictors for advertising avoidance were search hindrance and readers' perception that advertising was uninteresting.

In summary, research on advertising avoidance is somewhat limited in traditional media. The primary focus tends to be on television advertising avoidance since it has the highest rate of avoidance. Information on advertising avoidance in print media appears to be largely descriptive. While research suggests that content factors such as believability and differentiation may influence advertising avoidance, other evidence points to the mere presence of ads as a major contributor in consumers' decision to avoid them. 


\section{CONSUMERS' LOW ATTENTION TO ONLINE ADVERTISING}

Once the Internet became a marketing tool, the amount of advertising executed through it grew continuously (McCoy et al. 2007). Based on the research conducted by Rodgers and Thorson (2000) and Burns and Lutz (2006), online advertising may encompass 10 formats, as shown in table 2.1. According to Marketing Charts (2011), online advertising was expected to grow $23.3 \%$ from $\$ 154.9$ billion in 2011 to $\$ 191$ billion in 2012, and by 2016 another 7.8\%. Yet all these advertising expenditures have not produced satisfactory results. One way to assess advertising effectiveness is clickthrough-rate (CTR). CTR is also a financial tool for cost and revenue (Regelson and Fain 2006). In 1995, the average CTR was 2\%. It went down to 0.5 in 1999 (Neilsen 2000). Research conducted by Google (2010) suggested that in 2009 CTR decreased to $0.1 \%$. Researchers use these statistics to underscore the ineffectiveness of online advertising (Cho and Cheon 2004).

The in-attention towards online advertising has been pointed out as a reason for low CTR, since attention should precede action. Consumer response to advertising on the Internet is expected to be similar to that toward advertising in traditional media; the problem is attention grabbing on the Internet is much more difficult to achieve (Dreze and Hussherr 2003). According to Dreze and Hussherr (2003), the online advertising environment, where advertisements usually share bandwidth with other elements of a web page, greatly reduces attention to online advertising. Since people have a limited capacity of attention, to grab attention an advertisement must compete with other content. In other words, online advertising occupies only a small portion of the computer screen; 
the user's attention, in fulfilling her goals, is likely to be focused on other parts of the page. This facilitates in-attention to online advertising.

All of these characteristics challenge advertisers to grab the attention of consumers. Benway (1999) suggested "banner blindness," the phenomenon of people keeping their eyes away from anything that resembles banner advertisements (Benway 1999). Using eye-tracking, Dreze and Hussherr (2003) revealed that the level of attention paid to online advertisements is less than $50 \%$. Attention paid to advertisements on any other media is much higher. Dreze and Hussherr (2003) concluded that, online, people either intentionally or unintentionally avoid looking at advertisements.

Some researchers investigated the reduced attention to online advertisements by adopting the concept of attention inertia. For example, Wang and Day (2007) indicated that a user's attention allocated to online advertisements was gradually reduced because of attention to other web content that suits the user's goal. Hsieh and Chen (2011) pointed out attention inertia as major reasons for reduced attention. In their experiment, subjects viewed 10 webpages containing advertisements, and attention intensity level was measured. Attention to advertisements dropped dramatically after the first webpage, meaning that subjects become less responsive to advertisements with time.

The above review represents research on advertising avoidance phenomenon in the online environment. Cho and Cheon (2004) suggested that online advertising avoidance could be classified into three types: cognitive, affective, and behavioral avoidance. Among the three types of avoidance, cognitive and affective avoidance are strongly related to the aspects of "attention." Cognitive advertising avoidance is driven 
by the consumer's evaluative belief about online advertising. Therefore, if consumers evaluate online advertising negatively, it evokes cognitive avoidance. Second, affective advertising avoidance is led by consumer's emotional reaction to Internet advertising (Cho and Cheon 2004, p. 91). If consumers dislike online advertising altogether, they are less likely to pay attention to the source of their displeasure. Finally, behavioral advertising avoidance is when a consumer acts to avoid advertising. For example, a consumer scrolls down a web page or clicks away from an ad. This behavioral avoidance is distinct from lack of attendance. Dreze and Hussherr (2003) indicated, however, that at least a small amount of attention is paid to an advertisement just to lead to any action, including behavioral avoidance. Hence, the attentional aspect might be at the more initial stage of response.

Many researchers have delved into factors that promote advertising avoidance on the Internet (Cho and Cheon 2004; Edwards, Li and Lee 2002; Ha 1996). Cho and Cheon (2004) pointed out that perceived goal impediment, perceived advertising clutter on the web page, and prior negative experience regarding online advertising are important factors not only reducing attention to advertising, but also facilitating actions to get away from advertising. Research has also suggested that consumer motivation to use the Internet affects consumer attitudes towards Internet advertising (Rodgers and Thorson 2000). Edwards et al. (2002) further examined the perceived intrusiveness of online advertising as a predictor of withdrawing visual attention. Collectively all these studies investigated advertising ineffectiveness in the general Internet environment. Kelly, Kerr, and Drennan (2010) examined instead the predictors of advertising avoidance on a 
specific online platform, social networking sites (SNSs). What they found to be major factors of advertising avoidance in such an environment were perception of message relevance and skepticism of SNSs as a credible advertising medium. Since the amount of ads in SNSs is ever rising, more research is needed to understand consumers' attention, and response, to SNS ads.

\begin{tabular}{|c|l|}
\hline Banner ads & $\begin{array}{l}\text { Banner ads have a graphical component, are horizontal, rectangular- } \\
\text { shaped and usually located at the top or bottom of a web page (Zeff } \\
\text { and Aronson 1997). }\end{array}$ \\
\hline Skycraper ads & $\begin{array}{l}\text { Skycraper ads are the thin and vertical version of banner ads. They } \\
\text { appear along the side of a web page (Burns and Lutz 2006). }\end{array}$ \\
\hline Pop-up ads & $\begin{array}{l}\text { Pop-up ads open new web browser to display advertisement on top of } \\
\text { the content users browse (Rodgers and Thorson 2000; Burns and Lutz } \\
\text { 2006). }\end{array}$ \\
\hline Interstitials & $\begin{array}{l}\text { Interstitials are similar to pop-up ads, but are shown between two } \\
\text { pages while users wait for a content page. Therefore, interstitials, } \\
\text { unlike pop-up ads, do not interrupt user's activities (Rodgers and } \\
\text { Thorson 2000). }\end{array}$ \\
\hline Keyword ads & $\begin{array}{l}\text { Keyword ads refers to "advertisements offered by a search engine in } \\
\text { which advertisers select specific keywords (or search terms) and } \\
\text { develop a text ad to appear in search results pages when online users } \\
\text { perform information search using those keywords" (Yoo 2009, p. } \\
\text { 401). }\end{array}$ \\
\hline Hyperlinks & $\begin{array}{l}\text { Hyperlinks are highlighted words or phrases typically embedded in } \\
\text { content. Hyperlinks enable users to navigate to another site by simply } \\
\text { clicking on the highlighted words. }\end{array}$ \\
\hline
\end{tabular}

Table 2.1: Formats of Online Advertising 


\begin{tabular}{|c|c|}
\hline $\begin{array}{l}\text { Aditorials (paid } \\
\text { editorial ads) }\end{array}$ & $\begin{array}{l}\text { Aditorials (paid editorial ads) contain written opinions about products } \\
\text { or services that disguise as an editorial content on the Web page (Lal } \\
\text { and Rashimi 2011). }\end{array}$ \\
\hline E-mail ads & $\begin{array}{l}\text { E-mail ads are advertisements distributed by advertisers through e- } \\
\text { mails. }\end{array}$ \\
\hline Sponsorship & $\begin{array}{l}\text { Sponsorship is "an indirect form of persuasion that allows companies } \\
\text { to carry out marketing objectives by associating themselves with key } \\
\text { contents" (Rodgers } 2000 \text {, p. 1). }\end{array}$ \\
\hline Websites & $\begin{array}{l}\text { Websites such as corporate homepages currently serve the function of } \\
\text { advertising (Chen and Wells 2000; Singh and Dalal 1999). A Website } \\
\text { is perceived to be less intrusive than any other advertising formats } \\
\text { because it is based on a "pull" instead of "push" strategy (Rodgers } \\
\text { and Thorson 2000). }\end{array}$ \\
\hline $\begin{array}{l}\text { Social Network } \\
\text { Ads }\end{array}$ & $\begin{array}{l}\text { SNS ads can be defined as advertisements displayed on social } \\
\text { networking sites to generate additional revenue (Enders et al. 2008). } \\
\text { Therefore, they might be appropriately considered as an advertising } \\
\text { platform rather than a specific advertising format. Aside from email } \\
\text { ads, SNS ads can take almost all the aforementioned formats of } \\
\text { online advertising. Among them, banner ads, search ads, sponsorship, } \\
\text { and webpages are the primary forms (Enders et al. 2008; Canzer, } \\
\text { 2006). }\end{array}$ \\
\hline
\end{tabular}

Table 2.1 (cont.): Formats of Online Advertising

\section{ADVERTISING ON THE SOCIAL NETWORK SITES}

Social Network Ads can be defined as advertisements displayed on social networking sites to generate additional revenue (Enders et al. 2008). Aside from email ads, SNS ads can take almost all the aforementioned formats of online. The predominant forms are banner and search ads, sponsorship and webpages (Enders et al. 2008; Canzer, 2006). 
As a delivery mechanism of online advertising, SNSs have grown dramatically. They are now the most prevalent online activity, followed by email (Nielsen Online 2009). eMarketer (2012) estimated 1.43 billion social media users by 2012, and Facebook itself exceeded 1 billion users in October of 2012 (CNNMoney 2012). Due to its unprecedented growth, SNS has become a promising platform for advertising. SNSs enable marketers to reach consumers directly in their personal and private environment (Boyd and Ellison 2007). Now, over 90 percent of advertisers execute their advertisement through social media (eMarketer 2012).

Total spending on social network ads worldwide reached $\$ 5.2$ billion in 2011 and is expected to 10 billion by 2013 (eMarketer 2012). Interestingly, nearly half (in 2011 $\$ 2.54$ billion, $48 \%$ ) this expenditure comes from the US market alone. The spending in the US was predicted to rise to $\$ 3.63$ billion in 2012 (47\% of worldwide spending) and $\$ 5.59$ billion by 2014 (46.6\% of worldwide spending). Revenues generated from social network ads will compose approximately $12 \%$ of the entire online ad spending in the US by 2013 (eMarketer, 2011). These figures suggest that SNSs have indeed become an important advertising platform for advertisers.

Among SNSs, Facebook is the most prevalent advertising platform and it accounts for a large portion (approximately 70\%) of ad revenues. Other SNSs, including Twitter and Myspace, make up the rest 30\% (eMarketer 2012). According to research from eMarketer (2013), 40\% of global companies surveyed said that they plan to increase advertising spending on Facebook and $25 \%$ of them planned to spend more on Twitter. In spite of the current growth in ad spending on SNSs, eMarketer $(2011,2012)$ 
expects the growth rate to fall in years to come. This projection is based on the consumer's low attention to SNS ads and actual low CTR. In fact, research conducted by IDC (2008) found that Internet users are less patient with advertising on SNSs than any other form of online advertising. More than half of their survey subjects $(51 \%$ of 1,619$)$ indicated that advertisements on SNSs are annoying. Furthermore, CTR for ads on SNS were much lower than those from general online ads. This generally results in fewer purchases through social network ads. A study conducted by Webtrends (2011) reported that the CTR for ads on Facebook was only $0.063 \%$ in 2009 and $0.051 \%$ in 2010, about half of the average CTR for overall online advertising.

Why the greatly reduced attention to SNS ads? One reason might be found in consumers' motivation to use SNS; another might be the structural characteristic of SNSs. First of all, according to researchers, people using SNSs mainly seek to interact with others (social interaction) and be entertained (Shin, 2009; Kim, Kim and Nam, 2010). Bettman, Luce, and Payne (1998) maintained that people usually put a lot of effort into assessing what objects could help them accomplish their goals in lives. This holds true in the online environment, meaning that people are motivated to examine the contents that match their motivation for using the Internet. Therefore, people are more likely to pay attention to postings and comments from known others. They are also more likely to ignore anything resembling advertisements, which might be assessed as objects that interrupt their motivation.

Second, since communication in SNSs is fundamentally based on users' human networking, usually composed of well known others, any messages sent by unknown 
others (e.g., brands) might be easily recognized and eventually perceived as irritating. Therefore, "the relation-based network" users have through social media might affect the effectiveness of advertisement in SNSs.

In fact, Kelly et al. (2008) found that teenage consumers were likely to be skeptical and avoid advertisements in the SNS environment by ignoring or deleting the ads without even reading them. According to their research, teenagers said "I don't really notice them" (boy, 16 years), "There's so much dodgy stuff that you can't take any of it seriously" (boy, 15 years), "I don't pay any attention to them" (girl, 14 years), and "Just popping up on the screen and you just have to close them. I just close them straight away. I don't even look at them" (girl, 16 years). All of these subjects' comments reflect the reduced attention to SNS ads and negative attitude towards online advertisements. Kelly et al.'s (2008) research shows that teenagers considered advertisements in SNSs to be neither credible nor relevant to them. Such skepticism will no doubt contribute to the declining growth rates of ad spending on SNSs (eMarketer 2011; IDC 2008). However, Kelly et al.'s work is one of the very few formal studies scrutinizing advertising avoidance in the SNS environment. Also, since their study focused only on teenagers' ad avoidance, more research regarding avoiding SNS ads is greatly needed. As mentioned above, advertisers' first task is to grab consumers' attention and generate a favorable attitude. This is a significant issue for advertisers interested in the SNS environment. Therefore, this research will focus on key factors that might hamper attention to SNS ad and consumer response to attended ads (attitude toward the ad, attitude toward the brand, and purchase intention). 


\section{AD AVOIDANCE}

To better understand when people attend to advertising, we must investigate the mechanism behind advertising avoidance. More than two decades ago, Heeter and Greenverg (1985) posed this question: “Is zipping habitual or response to content?” (p. 17-18). Researchers and practitioners had no clear answer.

Cronin and Menelly (1992) proposed two types of TV commercial avoidance. The first proposition is referred to as the "discrimination mode." The discrimination mode considers avoidance behavior as a result of the cognitive processing of information. The discrimination proposition postulates that attention is allocated to opening portions of TV commercial for a certain period of time before attention is withdrawn. This proposition views the withdrawal of attention as a consequence of the cognitive information processing of the initial portion of the commercial.

Another form of advertising avoidance suggested by Cronin and Menerlly (1992) is "avoidance mode." The avoidance mode emphasizes that the mere recognition of an advertisement is enough to cause ad avoidance. It suggests there is no information processing. The avoidance proposition is theoretically based on learning theory, meaning that viewers learn to dislike commercials through repeated exposure. It views such behavior as automatic, not a consequence of information processing.

A great deal of previous research supports the importance of ad recognition or identification of inattention to ads (Cronin and Menerlly 1992; Benway 1999; Nordfalt 2005). Cronin and Menerlly (1992) ultimately concluded that, in the avoidance mode, almost nine out of 10 commercials were skipped. Even though there has been little 
research examining how advertising avoidance occurs on the Internet, some studies have supported the habitual avoidance behavior. For example, Benway (1999) emphasized "banner blindness" where people are less likely to pay attention to anything that looks like banner advertising. Dreze and Hussherr (2003) pointed out that people can easily recognize advertising without directly looking at it (low attention). Therefore, people are likely to ignore advertising intentionally in the online environment without deeply processing the contents. More recently, results from a study conducted by Hsieh and Chen (2011), which emphasized the concept of attention inertia, strongly supported the avoidance perspective.

The current research, to better understand the mechanism behind not only inattention to ads but also consumers' subsequent response, suggests as a theoretical explanation the persuasion knowledge model (PKM; Friestand and Wright 1994). In a vein similar to the avoidance perspective, PKM is based on learning theory; it also considers ad recognition (tactic perception) as an important predictor for consumers' defensive reaction.

\section{Persuasion Knowledge Model}

Many studies that have emphasized habitual avoidance have mentioned "learning theory." These scholars suggest that a consumer's previous knowledge and experiences are important in predicting consumers' reaction to advertising (Cronin and Menerlly 1992; Benway 1999; Nordfalt 2005; Cho and Cheon 2004). PKM (Friestand and Wright 1994) further explains the process of how previously accumulated knowledge and experiences implicitly influence people's response towards persuasive stimuli. 
PKM holds that one of the important missions people have as consumers is to effectively deal with marketing tactics such as advertising (Friestand and Wright 1994). To cope with marketing efforts, consumers accumulate persuasion knowledge, or schema, as they are, over time, exposed to diverse marketing activities. According to Friestand and Wright (1994), persuasion knowledge refers to a consumer's beliefs about the goals and effects of persuasion attempts, beliefs about the actions of agents, and beliefs about the consumer's own coping ability.

Once a consumer perceives activities that aim to influence his beliefs or attitudes (i.e., persuasion attempts or advertising), persuasion knowledge is automatically activated and the consumer generates a defensive mechanism. At this point, a consumer infers the motivations that led the agent to construct the persuasion attempt in a certain way (inference of persuasion motive). The consumer then predicts what possible effect the persuasion attempt might have.

Importantly, researchers have argued that the tactic perception leads consumers to respond automatically to advertising (Friestand and Wright 1994; Pillow 1991). In particular, Friedstand and Wright (1994) explained that as consumers repeatedly cope with certain persuasion attempts, they grow more familiar with the coping task. Consequently, the cognitive effort needed to cope significantly decreases; indeed, their coping behavior becomes habitual and automatic. Wright, Friestad, and Boush (2005) als o confirmed that consumers' coping activities become remarkably automatic and effortles $\mathrm{s}$ as their experience and knowledge about coping tasks increase. As a result of activation of persuasion knowledge and defense mechanisms, the amount of attention paid to 
persuasion attempts may drop off automatically. Advertising researchers have found significantly reduced attention toward advertising as a consequence of persuasion knowledge activation (Donthu et al. 1993; Goodstein 1993; James and Kover 1992).

In summary, once consumers perceive a persuasion attempt as a purposive tactic, their persuasion knowledge is automatically activated. As they grow accustomed to coping, they do it automatically when they perceive this tactic. If consumers fail to perceive a persuasion attempt as a tactic, then persuasion knowledge is of course less likely to be triggered and such consumers are more likely to accept the message. This research hypothesizes that once consumers recognize something as advertising, they are likely to have negative responses toward it habitually.

\section{Tactic Perception}

Therefore, consumers' recognition or identification of advertising is an important factor contributing to consumers' response to advertising. It is no many marketing tactics blur the boundary between content and commercial. This is done to minimize loss of attention and maximize ad effectiveness. In particular, product placement (PPL) and advertorials are common advertising strategies in traditional media to keep consumers from "identifying" advertising (Dix and Phau 2008). Product placement, or "embedded advertising" can be defined as a commercial content, brand name, product, symbol or package, embedded in a natural media environment, such as a television program, movie, or other form of media (Panda, 2004; Williams et al., 2011). Therefore, product placement can be seen as a combination of entertainment and commercial messages where audiences are naturally exposed to brand-related information as they process the 
media content (Williams et al., 2011). Balasubramanian et al. (2006) found that consumers might not consider PPL as a marketing tactic especially if there is a high level of relevance between the program and the product. Due to this advantage, marketers continue to up their spending on product placement. PQ Media (2012) expected global spending on product placement to exceed, by 2012, \$10 million dollars, an increase of over $10 \%$. America is the world's largest investor on product placement, accounting for nearly $60 \%$ of total spending in 2012 .

When an advertisement is masked as an editorial, usually in a newspaper or magazine, it is referred to as an advertorial. Advertorials have been widely used to attract readers' attention (Dix and Phau 2008). Kim (1995) found that consumers who read advertorials were normally unaware that what they had read was in fact an advertisement for products or services. Even though such advertorials have chiefly appeared in print media such as newspaper and magazine, the practice has recently emerged as an advertising format in the online environment (Lal and Rashimi 2011).

The common characteristics of these two advertising tactics can be the natural embedment of commercial content in non-commercial media contexts. Consistent with PKM, it highlights the importance of "advertising identification" or the concept of "tactic perception" in the consumer's responses to advertising. It can be assumed that since these two types of message delivery are not easily perceived as advertising, these are less likely to activate persuasion knowledge, which usually generates skepticism.

Even though consumers' reduced attention and negative response is much more prevalent in online media, especially in SNSs, little research has investigated ways to 
prevent this in the SNS environment. Therefore, this study would examine what drives the loss of attention to SNS ads. By doing so, it would ultimately provide valuable guidelines for improving SNS ad effectiveness.

\section{AD LOCATION IN SNS}

There have been several studies that emphasize the impact of design elements of online advertising on online ad effectiveness (Lin and Chen 2009; Lohtia et al. 2003; Kim et al. 1997). In the case of the online environment, online ads are not spotlighted; they usually share bandwidth with other contexts of a web page. Dreze and Hussherr (2003) even mentioned that this environment devastates advertising effectiveness, arguing that ad location is one of factors that could improve the level of attention to online advertising. As such, ad placement among several design elements could be an important issue to get through the clutter of web pages and grab customers' attention. In fact, many studies have investigated how ad position affects a consumer's response to online advertising (Kim et al., 1997; Calisir and Karaali 2009; Lin and Chen, 2009).

Kim et al., (1997) in particular greatly emphasized the importance of ad position on online ad effectiveness. First of all, they discovered that the banner ads located about $1 / 3$ of the bottom of the web page can increase approximately $77 \%$ of CTR over ads located at the top. Furthermore, they revealed that ads placed on the side of the page, right next to the scroll bar can also increase CTR by $228 \%$ over ads placed at the top. In a similar vein, Nielson (2000) suggested the upper-left corner of web page to be an effective place to have any brand-related information. These results strongly support the argument that ad placement influences consumer response. Lin and Chen (2009) recently 
found an interaction effect between ad type and ad position. They explained that promotion-type of advertising is more effective when placed in the middle of web page; commodity-type advertising is more effective at a low position.

Some researchers have investigated how different proximities between target information and distractor information (e.g., advertisement) impacts evaluation of distractor information under high levels of goal-oriented tasks. Raymond, Fenske, and Westoby (2005) revealed that distractor placed near the target is less favorably evaluated than distractor placed far from the target, emphasizing the location-based inhibition. Applying this theoretical underpinning to the wider advertising field, Panagiotidou and Vivas (2009) argued about the ineffectiveness of online pop-up advertising, which covers or appears on the same page as target information. This type of advertising inhibits a consumer's goal in using the Internet, causing the consumer to ignore and devalue advertising. Further, Duff and Faber (2011) revealed an interaction effect on advertisement evaluation between distance separating ad and target contents and similarity of ad and target contents. They asked subjects to navigate eight different web pages to perform particular given tasks. They then asked subjects to evaluate brands they saw during their task performance. They found that when advertisements were placed near target information and were visually analogous, brands were more likely to be devaluated than brands placed far and visually dissimilar from target information.

However, more research is needed regarding the effect of ad position in the SNS environment. Depending on the SNS, an ad's location can vary. Facebook places about six banner ads on the right-hand column of the page or inside the timeline under the name 
of either the user (related posts) or brand (suggested posts or sponsored story) (Adweek 2013). MySpace usually places ads in the upper right hand corner of the page as a "brick." Twitter has a form of advertising known as "promoted accounts." They usually show up on the left side of a user's Twitter stream. These promoted accounts recommend a user to follow a suggested account based on the user's specific interests. Like Facebook, Twitter also advertises products or brands through "promoted tweets," located inside individual users' timelines (GIGaom 2012).

The unique patterns of ad location in SNSs are that they enable advertisers to place advertising both inside and outside SNS users' personal timelines. (See figure 2.1, 2.2 and 2.3) Users pay attention to their timelines because this is where they most often interact with friends. Therefore, ads placed in a user's timeline along with other content might help an ad to receive attention. Areas outside of a user's timeline where most banner ads appear are easily ignored. Therefore, this study postulates that the two distinctive ad locations (inside vs. outside of the timeline) would generate different levels of attention and consumer response.

\section{ADVERTISING PATH}

In SNSs, an advertisement can be conveyed to consumers through two primary ways — either a direct or indirect path (Mangold and Faulds, 2009). (See figure 2.1, 2.2

and 2.3) First, direct advertising can be defined as advertising posted or sent directly from specific brands or marketers in SNS environments without any third party endorsement. As do marketers in other forms of web pages, marketers in the SNS environment can deliver advertisements directly to their target customers mostly in the form of banner 
advertising, the most prevalent advertising form in the SNS environment (Enders. 2008; Canzer, 2006; Jothi et al. 2011). For example, with Facebook, users might see banner advertising in the form of "suggested posts" or "standard ads" directly from brands. Also, MySpace executes the direct advertising on the top of the page in the form of a banner. Such advertising not only promotes specific products or services, but also fosters consumer traffic to certain content or to fan pages. Bonneau (2008) suggested banner advertising as a good way for SNS operators to make a profit, though he stressed the need for more research on it.

Ad indirect path for advertising (i.e., pass-along) can be referred to as advertising conveyed under a third party's name. Pass-along advertising in SNSs is akin to WOM except on a much greater scale (Mangold and Faulds, 2009). Beyond just one-to-one or one-to-many communication, SNSs enables consumers to disseminate information to hundreds or even thousands of people who have online relationships (e.g., friends on Facebook, followers on Twitter). Twitter users can pass along product-related information or commercial content via the "re-tweet" function. In Facebook, users can do so by using the "like," "comments," or "share" functions on commercial or noncommercial postings. These pass-along advertising might appear as "related post", "sponsored stories", or "retweeted post" in other users' timelines. Therefore in social media, it is difficult for marketers to have control over contents or frequency of consumer-generated, brand-related information (Mangold and Faulds, 2009). However, marketers today seem to have control over the pass-along information. For example, on Facebook, if one user clicks the "like" button on a certain brand, the brand-related 
commercial or information could appear in others' timelines both at that instant and much later. According to the advertising guide published by Facebook (2013), marketers can choose their target as people who have a friend connected to their brand, so that these targets are able to see ads where their friends' names are included. According to Facebook, people are more likely to engage with these types of advertisements. This research hypothesizes that this is possible because users might hardly recognize it as advertising due to their friends' name shown as a message sender (low level of tactic perception).

Since most of the online relationships in SNSs are based on users' existing social network, information provided by other users is perceived as being more reliable than that from strangers or advertisers (Chu and Kim, 2011). Social media itself is thus considered to be a more trustworthy and reliable information source than any other brand-promoted communication (Foux, 2006; Mangold and Faulds, 2009). Consumers are thought then to rely more on social media for their purchase decision making (Vollmer and Precourt, 2008).

These two advertising paths are expected to generate different impacts on consumers' attention to advertising and, in turn, on advertising effectiveness. First we should note that consumers' motivation to use SNS is to communicate and build relationships with known others (Chu and Kim, 2011). Given this fact, consumers might easily recognize contents that has other purposes (e.g., promotes consumption) sent from unknown others or advertisers. Knowing this leads to loss of attention and unfavorable responses. Even though both forms of content contain all the same information regarding 
a certain brand, a friend's name included in the pass-along information might blur the boundary between a commercial and a friend's sharing of information.

Further, because of the conflict between consumers' SNS usage and commercial content, consumers might feel a high level of interruption by such content, a negative consequence for advertising. Moreover, as previous newspaper research has indicated, people identify stimuli as an advertisement when there is brand name as a sponsor (Wilkinson et al. 1995). Since the names of content providers, either a brand's or a friend's name, is displayed, the ad path is expected to influence consumers' responses to SNS advertisements. 


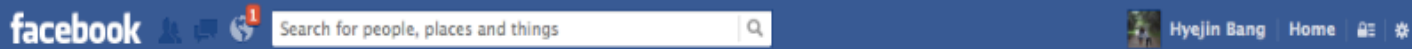

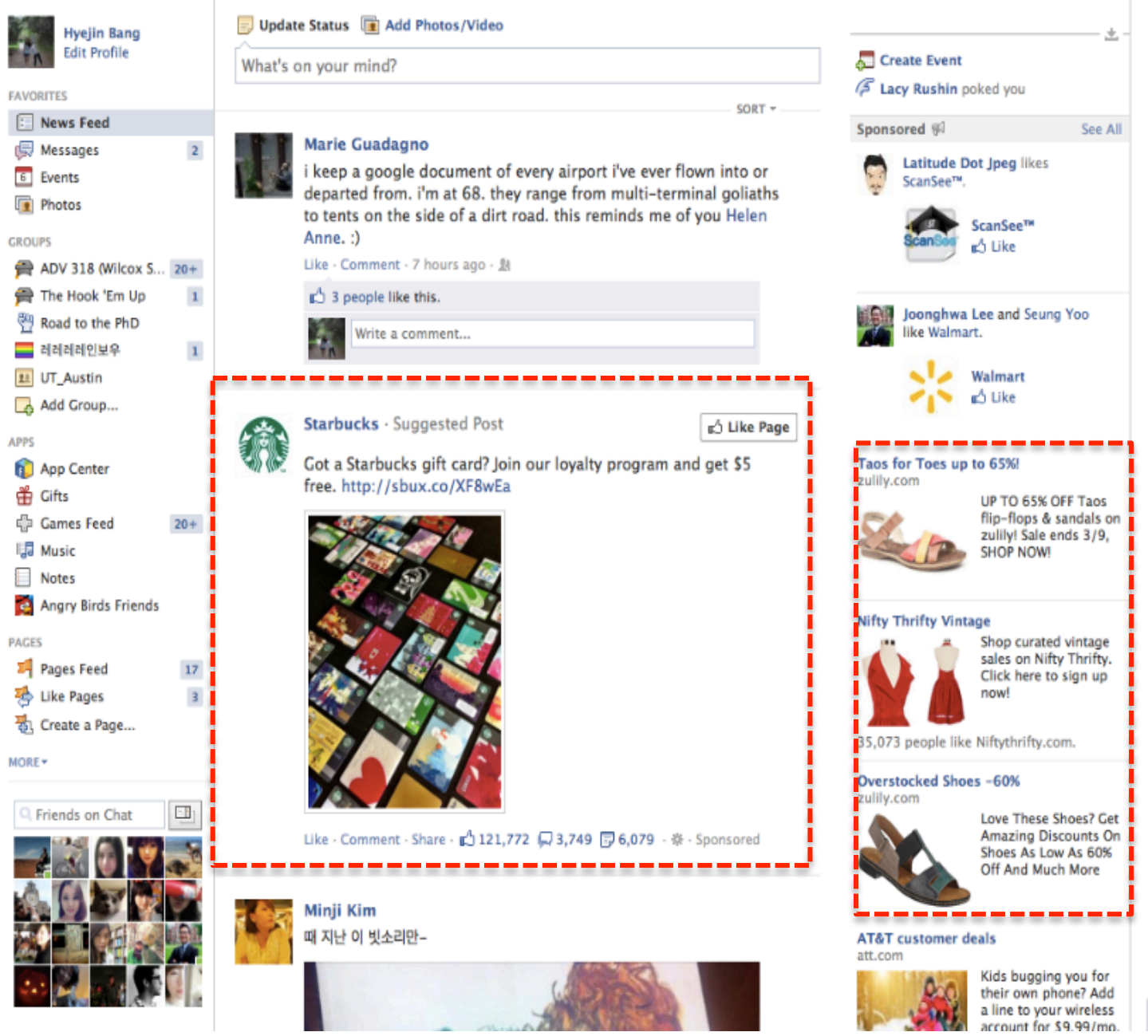

Figure 2.1 Examples of Direct and Inside SNS ad (left) and Direct and Outside ad (right) 


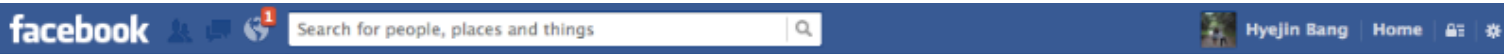

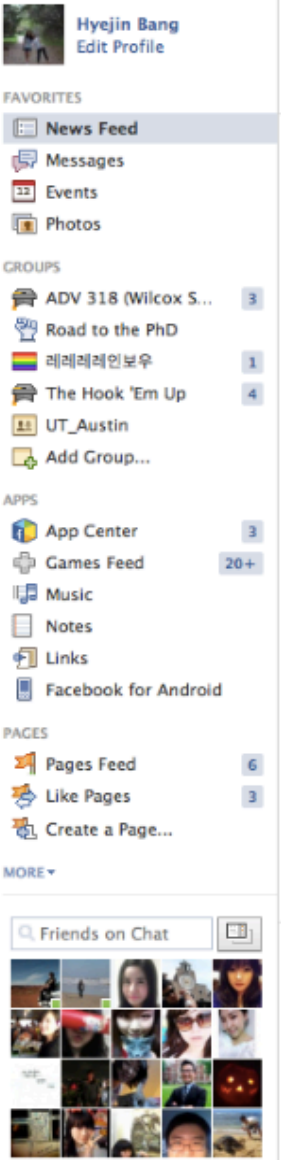

Update Status Add Photos/Video
How's it going, Hyejin?
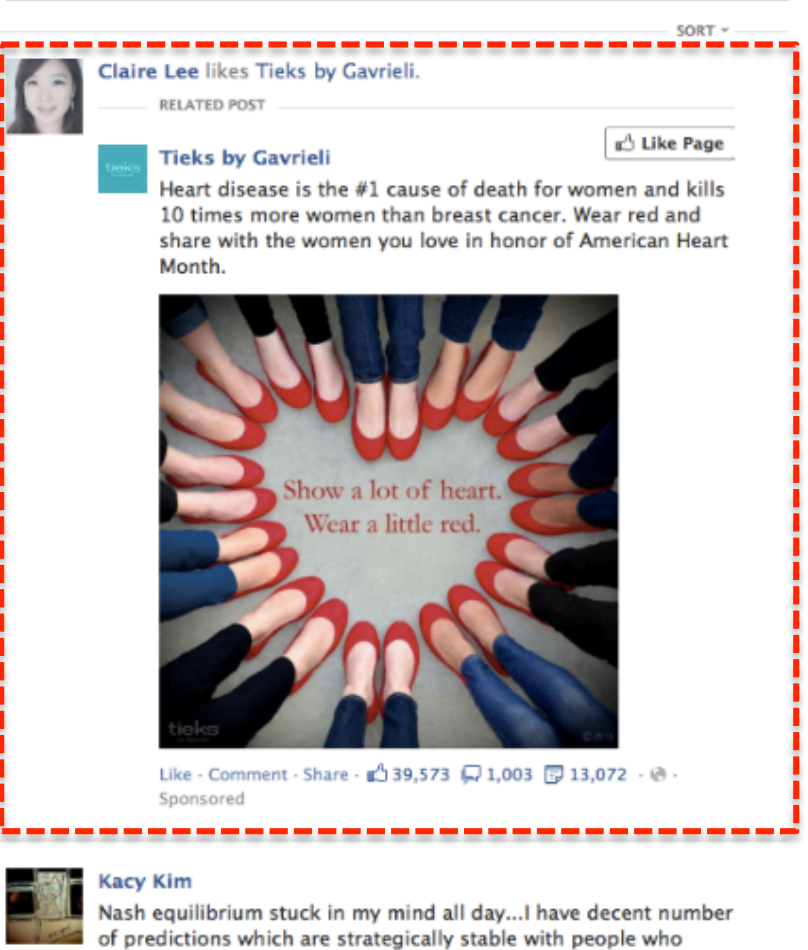

Kacy Kim

Nash equilibrium stuck in my mind all day...I have decent number of predictions which are strategically stable with people who know their best/or close to their best responses with decent rationality. However, I also struggle with people who give me difficulty to find an equilibrium. I know this statement has many flaws to address accurate NE, but really... is it too much to expect an equilibrium-like mutual interaction in a real life with real people? My irrationality makes me sick my rationality and vice versa.
Create Event

P 1 request from Latitude Dot Jpeg

62 other app requests

Sponsored की

See All

Cute Shoes Up to $65 \%$ off

zulily.com

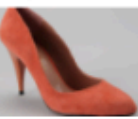

Sandals, heels, and Shop today - sale ends $2 / 14$

Recent College Graduates honda.com

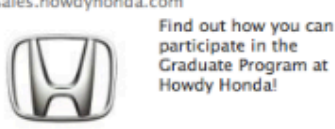

Zappos@ Boots Under $\$ 100$ zappos.com

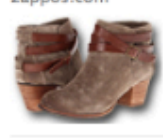

A great pair of boots 't have to break

Create Your Career Path visit. artinstitutes, ed

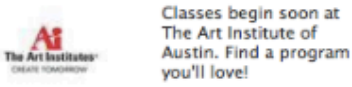

Eco-Friendly Rings

brilliantearth.com Discover Brilliant

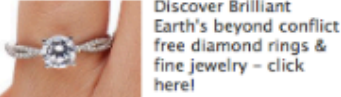

Overstock UCC Boots: \$13? rewardszoneusa.con

Cet a Pair of Women's
UCC Boots for $\$ 13$. imit 1 Per Customer.

Figure 2.2 Examples of Indirect and Inside SNS ad 


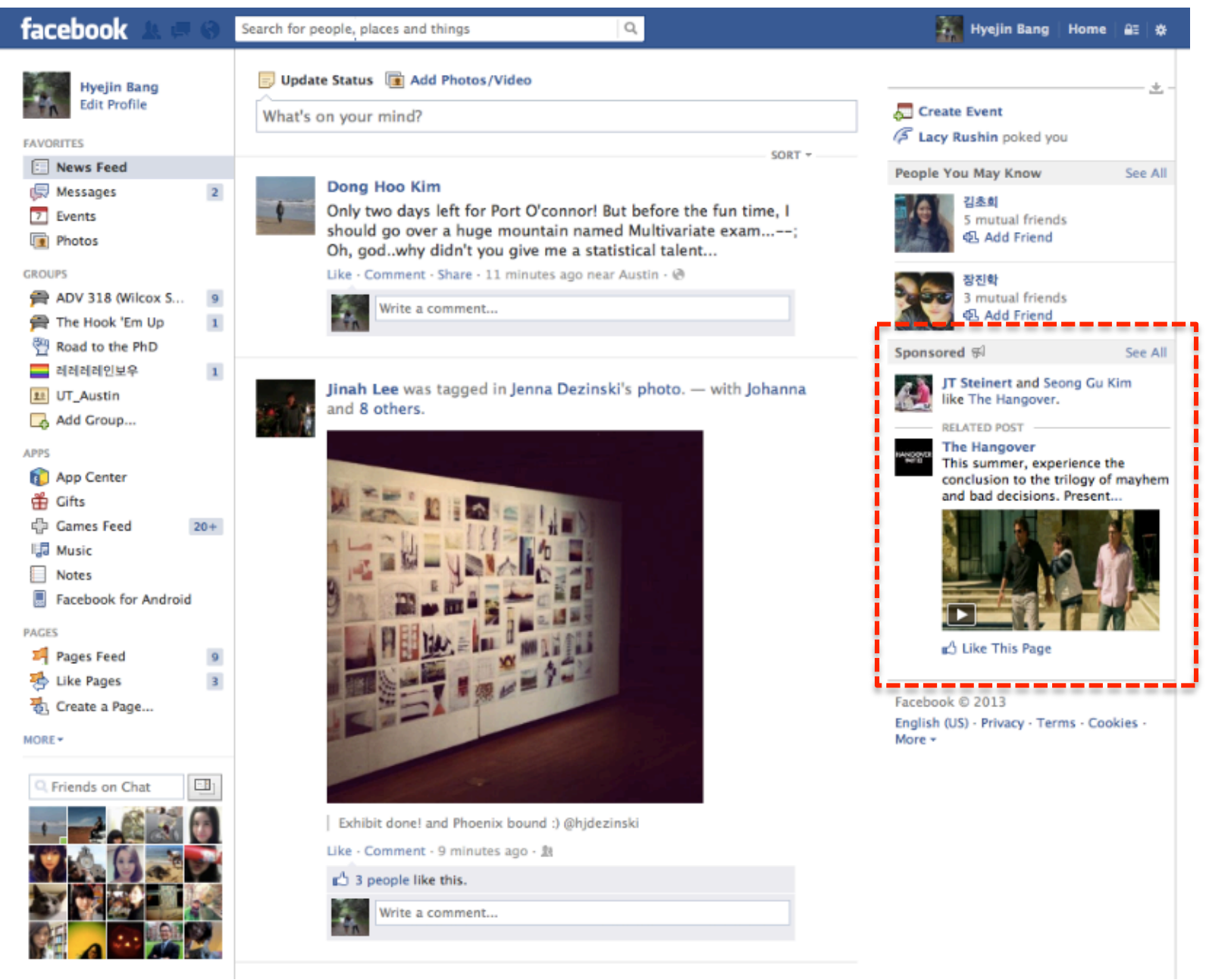

Figure 2.3 Examples of Indirect and Outside SNS ad 


\section{CHAPTER 3: FRAMEWORK AND RESEARCH HYPOTHESES}

Notwithstanding consumers' responses to SNS ads being quite negative, growth in SNS ads has continued unabated. Most research on SNS ads has indicated that consumers perceive them to be annoying, irritating, and not credible (IDC, 2008; Kelly, Kerr, and Drennan , 2010). The CTR for SNS ads has been much less than CTR from general online ads (Webtrends, 2011).

Friestand and Wright's (1994) PKM indicates well the mechanism underlying such responses. They argue that once consumers perceive a persuasion attempt as a purposive tactic, they are more likely to recognize the motive behind the persuasion attempt and generate a defensive mechanism such as avoidance or loss of attention. On failing to perceive it as a tactic, one is less likely to have persuasion knowledge triggered and more likely to accept the message. We can hypothesize then that once consumers recognize something as advertising, they are likely to ignore it-consciously or otherwise. Should they still pay the ad attention, their response to it will be much lower.

As a factor affecting consumers' awareness of a persuasion attempt as "tactic," the accessibility of the agent's hidden motive has been examined (Campbell and Kirmani, 2000). In this research, we suggest that the interaction effect of ad location and ad path in SNSs will either facilitate or hamper the tactic's perception (accessibility of the agent's hidden motive), which finally influence consumers' responses to advertisements.

In the literature, scholars have investigated how ad position/ location affects a consumer's response to online advertising (Kim et al., 1997; Calisir and Karaali 2009; Lin and Chen, 2009). What is interesting about the ad location pattern in SNSs is that 
advertisers can place ads both inside and outside a person's timeline. However, users are more likely to be trained over time to pay attention to their timelines, where they most often interact with known others. Therefore, advertisements placed in users' timelines along with other content in a similar format is expected to challenge consumers' ability to identify ulterior motives, better enabling an ad to grab attention. Likewise, SNS users are likely to be trained to ignore that area outside their timelines where most banner ads appear.

Second, the two possible paths of advertising, direct and indirect, are the major characteristics of SNS ads (Mangold and Faulds, 2009). Since most of the relationships people have in SNSs is based on their' real-life human network, information sent by other users (e.g., friends or followers) are considered to be more credible than information from unknown others such as advertisers (Chu and Kim, 2011). "Communication” and "relationship building" with their known others are what these consumers want (Chu and Kim, 2011), so they might automatically be suspicious of content sent by unknown others (advertisers). Such suspicion leads to less attention given and, should attention be given, negative responses towards the contents.

As people become more familiar with SNSs, they are likely to become adept at distinguishing informational content from advertising, which in turn affects advertising effectiveness. The interaction of the two factors - ad location and ad path — is expected, first, to cause variance in consumers' attention to SNS advertisements and second, to influence consumers' attitudes toward attended ads. As an The first hypothesis is developed to test consumers' varying attention levels. 
H1: Consumer attention to the ad will differ based on ad position and ad path in the SNSs

More specifically, since inside of their timelines people communicate (comments, posting, sharing) only with known others, they are more likely to perceive this space as private and to expect content there from people with whom they have connections through SNSs. Therefore, if users receive advertisements inside their timelines, indirectly, from known others, they are more likely to perceive it as a type of communication, such as information sharing. Hence, the accessibility of a hidden motive behind the advertisement should become much lower, as should their defensiveness.

If users receive ads, directly, inside of their timelines, they are likely to be suspicious and feel a high level of interruption. Ultimately, this should lead to the accessibility of a hidden motive being high. Therefore, when advertisements are located inside users' personal timelines, those from advertisers are less likely to generate positive responses than those from known others. Thus:

H2a: When an ad is located within the user's timeline in the SNSs, the ad from indirect path (friends) will generate more positive Aad than that from the direct path (the brand).

H2b: When an ad is located within the user's timeline in the SNSs, the ad from indirect path (friends) will generate more positive $\mathrm{Ab}$ than that from the direct path (the brand). 
H2c: When an ad is located within the user's timeline in the SNSs, the ad from indirect path (friends) will generate more positive PI than that from the direct path (the brand).

However, since users do not usually communicate or share information with relation-based known others outside the timeline, any posting outside their timeline is likely to be perceived as a type of marketing communication such as advertising. Specifically, when the posting is sent by known others, they might automatically feel that marketers take advantage of their relationship as a marketing tactic, which might backfire against marketing tactics. Consequently, the accessibility of an ulterior motive behind the advertisement becomes much higher. Because of the adverse effect, consumers might be much more skeptical of the ad placed inside their timeline, and consumers will likely generate much stronger defense mechanisms, leading to negative response. Therefore, this research expects, the indirect path, when ads are located outside users' timelines, to be less effective than the direct. Thus:

H3a: When an ad is located outside of the user's timeline in the SNSs, the ad from the direct path (the brand) is more likely to generate positive Aad than that from the indirect path (friends).

H3b: When an ad is located outside of the user's timeline in the SNSs, the ad from the direct path (the brand) is more likely to generate positive $\mathrm{Ab}$ than that from the indirect path (friends). 
H3c: When an ad is located outside of the user's timeline in the SNSs, the ad from the direct path (the brand) is more likely to generate positive PI than that from the indirect path (friends). 


\section{CHAPTER 4:RESEARCH METHODOLOGY}

\section{OVERVIEW AND RESEARCH DESIGN}

This chapter provides an overview of the study design, stimuli, variable measurement, and experimental procedure. The major objective of this study is to investigate the influence of SNS ad location and pass-through path on consumers' response to the ad. To test these hypotheses, a $2 \times 2$ between subject experimental design (Ad location: inside vs. outside x Ad path: direct vs. indirect) was employed. Both variables were manipulated in an experimental setting. The study design is presented in Table 4.1.

\begin{tabular}{|l|c|c|c|}
\cline { 3 - 4 } \multicolumn{2}{c|}{} & \multicolumn{2}{c|}{ Ad position } \\
\cline { 3 - 4 } \multicolumn{2}{c|}{} & Inside of Info Flow & Outside of Info Flow \\
\hline \multirow{3}{*}{ Ad Path } & Direct & & \\
\cline { 2 - 4 } & Indirect & & \\
\hline
\end{tabular}

Table 4.1 Study design

\section{STIMULUS DEVELOPMENT}

The SNS selected was Facebook because (1) Facebook accounts about 70\% of all SNS ads (eMarketer, 2012), and therefore, (2) Facebook receives the most attention as an advertising platform among the numerous available SNSs. To create a simulated Facebook page, a real Facebook page was captured using ACA Software, which allows the capture of long webpages. The subjects were in this way able to scroll up and down as they would normally do on Facebook. 
According to an earlier study, the product category that SNS consumers most frequently communicate about is food and drink (e.g., coffee, ice cream, and candy) (Moon and Lee 2012). Among these categories, coffee product has been often used in consumer-brand relationship study (Chang and Chieng 2006; Moon and Lee 2012), this research selected coffee brand as the product for the main experiment. A real coffee brand Blenz, was used. Blenz exists only in Vancouver, Canada. Therefore, it was assumed to be relatively obscure to American consumers. Subjects who recognized it were excluded from data analysis.

Four versions of a Facebook page were created. In this study, ad position was manipulated by placing the ad inside or outside of the user's timeline. An inside ad was placed alongside other postings in users' personal newsfeed. On the other hand, an outside ad was located on the right side of the Facebook page. Further, direct path was manipulated by showing brand name and logo at the top of an ad to indicate the ad sender. Direct path ad was conveyed as a form of "sponsored/ suggested post." In case of indirect path, on the other hand, subjects were asked to consider the message as having been delivered from one of five known others who subjects wrote down at the beginning of the experiment. The ad was shown as a form of "related post." Each ad consisted of both text and a pictorial image about a Blenz' 20\% discount event. (Appendices A and B show the stimulus materials).

\section{PRETEST}

Before the main test, a pretest was conducted to confirm the different levels of tactic perception according to ad location and ad path in SNSs, levels that were assumed 
to alter consumers' reactions to the ads. Since the questions per se, asking subjects about tactic perception, could affect their responses in main test (e.g., Aad, Ab, PI), pretest was conducted to confirm the different level of tactic perception. Participating were a total of 60 undergraduate students of the University of Texas at Austin. Every 15 of these students was randomly assigned to one of four conditions; they were given the stimulus developed above. Ad perception was measured by four items: "I think the posting is sponsored by Blenz Coffee;" "I think the posting is paid for by Blenz Coffee;" "I think the posting intends to encourage people to purchase the product by Blenz Coffee;" and "How do you perceive the posting? ( 1 = advertising, 7 = sharing of information)" A series of independent-samples t-tests were conducted to confirm the assumption that ad location and ad path vary the levels of tactic perception. The Cronbach's $\alpha$ for ad perception was .86 .

It was found that there is a significant difference in ad perception based on the location of the ad (t[-2.82], $\mathrm{p}<.05)$. Specifically, when the ad is located inside the user's timeline $(M=4.14)$, subjects were less likely to perceive it as advertising than when the ad is located outside $(\mathrm{M}=5.40)$. Further, the ad path has a significant impact on ad perception $(\mathrm{t}[-4.55], \mathrm{p}<.001)$. As expected, subjects assigned to indirect path $(\mathrm{M}=3.85)$ showed low level of tactic perception than those who were assigned to the direct path ( $\mathrm{M}=5.67)$.

Therefore, it confirms our prediction that the degree of tactic perception would vary depending on ad location and ad path. 


\section{MAIN EXPERIMENT}

\section{Subjects}

Total of 292 undergraduate students of the University of Texas at Austin were participated in the study on Mar Feb.4 though Feb. 20 in 2013. These subjects were recruited from the advertising participation pool (http://adresearch.advertising.utexas.edu/Participant_Pool/) in the Department of Advertising at UT Austin. These subjects consisted of $62 \%(n=181)$ males, and $38 \%(n$ $=111)$ females; subjects' ages ranged from 18 to 24 with an average of $21.4 .21 .8 \%(\mathrm{n}=$ $67)$ of subjects were freshmen, $19.5 \%(n=60)$ were sophomores, $32.1 \%(n=99)$ were juniors, and 19.1\% $(\mathrm{n}=62)$ were seniors.

\section{Procedure}

The study was run in online setting. Subjects were randomly assigned to one of the four between-subjects conditions: 2 ad location x 2 ad path. Subjects were first informed that the objective of the study was to extend the understanding of the diverse usage patterns of SNSs among college students.

The first step of the experiment was to make subjects perceive the experiment's Facebook page appear as their own. Subjects were asked to imagine themselves navigating Facebook for a while. And then, subjects were asked to write down the names of five Facebook friends with who they most often communicate. They were then asked to use each name to fill in the different colors of blank left at the top of Facebook postings, which appears in the next page. It helped increase the participants' immersion level in the Facebook usage situation. Also, those names were later used as a mechamism 
to manipulate one of the independent variables, ad path.Then, subjects were exposed to a Facebook page. The amount of navigation time given to the each subject was 90 seconds, and subjects were asked to scroll up and down while to look at its contents. Subjects assigned to the "indirect ad path" condition were asked to think the name of one friend as the sender of the ad (See Appendix B). In case of subjects assigned to the "direct path" condition, they were given the ad stimuli with 'Blenz Coffee' as the sender of the ad at the top of the ad posting (See Appendix A).

After the simulated navigation, subjects answered a series of questions about advertising recognition and advertising effectiveness (Aad, Ab, PI). The approximate time to complete the study was 20 minutes.

\section{INDEPENDENT VARIABLES AND MANIPULATION}

\section{Ad position}

In the current study, ad position is operationalized as the place where an advertisement is located in the social networking environment. In most previous studies, ad position has been manipulated by placing the ad at the top, in the middle, or at the bottom of a webpage (Kim et al., 1997; Lin \& Chen, 2009). Paying attention to two different ad positions in SNS environment, however, this study manipulated ad position by placing the advertisement inside or outside of the newsfeed. The ad placed inside the information flow was included in the user's timeline alongside other postings (See Appendix A). On the other hand, an ad placed outside of the information flow was placed at the right side of the Facebook page (See Appendix B). 


\section{Ad path}

Ad path was conceptualized as the path by which a certain ad is conveyed in an SNS environment either directly by brand or passed through by a user's friend (indirect). Since an advertisement can be delivered to consumers through two ways - a direct or indirect path (Mangold and Faulds 2009), ad path was manipulated by showing different two message senders (Friend vs. Blenz Coffee). The direct ad path was manipulated by displaying the brand logo and name at the top of an ad posting (See Appendix A). Subjects assigned to the direct ad path saw "sponsored/ suggested post" tag with the given advertisement. On the other hand, by leaving a blank for the message sender, subjects assigned to the indirect ad path would substitute one of their friends' names. Subjects would thus perceive the message as having been delivered from a person with whom they have a relationship in the SNS environment.

\section{DEPENDENT VARIABLES AND MEASUREMENT}

\section{Attention}

As a pre-analysis to explore consumers' attention to SNS ads, consumers' level of attention to the manipulated ads was measured and analyzed. In Hsieh and Chen's (2011) study, the number of subjects who were able to recognize the advertisement (recognition) was used as a measure for attention to online ads. Adapting the concept to this study, subjects were asked the question, "Did you see any posting regarding Blenz Coffee in Facebook page?" immediately after 90 seconds of forced exposure to the page. Subjects who said they did not see the ad were excluded. Each condition was not closed until there were about 40 subjects who indicated they saw the ad. 


\section{Advertising Evaluation (Aab, Ab, PI)}

Consumer response to the SNS ad was measured to gauge advertising effectiveness. Ad effectiveness was measured by attitudes toward the ad (Aad), attitudes toward the brand $(\mathrm{Ab})$, and purchase intention $(\mathrm{PI})$. Aad was measured on a 7-point semantic-differential scale anchored by Bad/ Good, Unfavorable/ Favorable, and Unpleasant/Pleasant (MacKenzie and Lutz 1989). Ab was also measured on a 7-point semantic-differential scale with three items of Bad/ Good, Unfavorable/Favorable, Negative/Positive (Lee and Aaker 2004). Finally, subjects' purchase intention was measured with a 7-point, semantic-differential scale consisting of three items (Unlikely/Likely, Improbable/Probable, Impossible/Possible) developed by Haley and Case (1979).

\section{ADDITIONAL MEASURE}

Additionally, subjects were queried on how much they used media and SNS per day. At the end of the experiment, demographic information, such as gender, age, ethnicity, major, and academic year was also collected. 


\section{CHAPTER 5: DATA ANALYSIS AND RESULTS}

\section{RELIABILITY TEST}

To examine the internal consistency of scale used in the study, the Cronbach's $\alpha$ test was conducted. The results are shown in Table 5.1. Attitude towards the ad, attitude towards the brand, and purchase intention were measured as dependent variables. As shown in Table 5.1, all three dependent measures were reliable across conditions.

\begin{tabular}{lll}
\hline \multicolumn{1}{c}{ Major Constructs } & \# Of Items & $\alpha$ \\
\hline Attitude towards the ad & 3 & .896 \\
Attitude towards the brand & 3 & .938 \\
Purchase Intention & 3 & .916 \\
\hline
\end{tabular}

Table 5.1: Reliability Analysis of Measurement Items

\section{MANIPULATION CHECK}

In order to check the efficacy of the manipulation of the two independent variables (ad location and ad path), independent sample t-tests were conducted. Subjects were asked to answer a series of manipulation check questions and (see Table 5.2). As addressed below, the two independent variables were successfully manipulated in the study.

First, the manipulation checks for ad location in SNS ad were conducted. Subjects were asked to indicate the extent to which location of the given advertisement was related to ratings from 1 (strongly disagree) to 7 (strongly agree). As expected, subjects assigned to the inside design indicated a higher rate $(M=5.49)$ for the question, "I think posting regarding Blenz Coffee was located INSIDE of my Newsfeed" than subjects assigned to the outside location $(\mathrm{M}=3.11, \mathrm{t}[10.00], \mathrm{p}<.001)$. On the other hand, subjects assigned 
to the outside location indicated a higher rate $(\mathrm{M}=5.11)$ for the question "I think posting regarding Blenz Coffee was located OUTSIDE of my Newsfeed" than did subjects assigned to the inside location $(\mathrm{M}=2.71, \mathrm{t}[-9.59], \mathrm{p}<.001)$.

Second, manipulation checks for the ad path were also conducted. Again, subjects were asked to indicate the extent to which the ad path was related among ratings from 1 (strongly disagree) to 7 (strongly agree). As expected, for the question "I think posting regarding Blenz Coffee was sent directly by Blenz coffee," subjects assigned to the direct location indicated a higher rate $(M=5.40)$ than did subjects assigned to indirect path $(\mathrm{M}$ $=4.48, \mathrm{t}[3.625], \mathrm{p}<.001)$. On the other hand, for the question "I think posting regarding Blenz Coffee was sent indirectly by my friend," subjects assigned to indirect path indicated a higher rate $(M=3.67)$ than did subjects assigned to the direct path $(M=2.41$, $\mathrm{t}[-5.264], \mathrm{p}<.001)$. Accordingly, the two independent variables were successfully manipulated in the study.

Additionally, subjects were asked to indicate the degree of perceived similarity between the given Facebook page and a real Facebook page $(1=$ very dissimilar, $7=$ very similar). Subjects perceived them as being very similar $(M=5.76)$.

- I think posting regarding Blenz Coffe was located INSIDE my

Ad Location Newsfeed

- I think the posting regarding Blenz Coffee was located OUTSIDE my Newsfeed

- I think the posting regarding Blenz Coffee was sent indirectly

Ad Path by my friend

- I think the posting regarding Blenz Coffee was sent directly by Blenz Coffee

Table 5.2: Manipulation Check Questions 


\section{HYPOTHESIS TESTING}

Before testing the hypotheses, the study analyzed subjects' general online/SNS usage patterns. All subjects were Internet users; only two were not SNS users. $1.4 \%$ of subjects reported that they spent less than an hour online each day; $30.5 \%$ of subjects $(\mathrm{n}=$ $89)$ spent 1-3 hours online each day; 39.4\% $(\mathrm{n}=115)$ spent $3-5$ hours, $21.6 \%(\mathrm{n}=63)$ spent 5-7 hours, and the rest $(7.2 \%, \mathrm{n}=21)$ spent more than 7 hours online each day. Regarding the time spent on SNSs, 9.9\% $(n=29)$ spent less than 30 minutes; $22.3 \%(n=$ $65)$ spent 30 minutes to an hour; $28.8 \%(n=84)$ spent $1-2$ hours; $19.9 \%(n=58)$ spent 23 hours; $8.2 \%(\mathrm{n}=24)$ spent $4-5$ hours, and $10.3 \%$ of subjects spent more than 4 hours on SNSs each day. As for types of SNSs frequently used, subjects mentioned Facebook, Twitter, Pinterest, LinkedIn, MySpace, and YouTube.

\section{Attention}

In this research, the level of attention was assessed prior to measuring consumers' responses to SNS ads as an exploratory attempt to examine attention in SNSs. Overall, $43.4 \%$ of subjects $(n=128)$ replied that they did not see any advertisement while navigating the Facebook page. Specifically, as shown in the Figure 1, the level of attention varied depending on the interaction of ad position and path. In Figure 1, the shaded bar indicates the number of subjects who paid attention to the advertisement, whereas the solid bar indicates the number of subjects who did not pay attention to the advertisement—ad avoidance.

In the case of inside timeline ads, the level of attention was quite high regardless

of ad path. Specifically, six subjects did not pay attention whereas 44 subjects paid 
attention to inside/indirect ads. Nine subjects missed inside/direct ad when 44 subjects paid attention. Overall, the level of attention was relatively low in the case of outside timeline ads compared to inside timeline ads. 62 subjects did not pay attention whereas 38 subjects paid attention to outside/ indirect ads. Especially, subjects' attention to outside/ direct ads was remarkably low. 129 subjects missed outside/ direct ad when 40 subjects paid attention.

It appears that the level of attention varies depending on ad location and ad path. The level of attention in order from high to low is: inside-indirect ad, inside-direct ad, outside-indirect ad, and outside-direct ad.

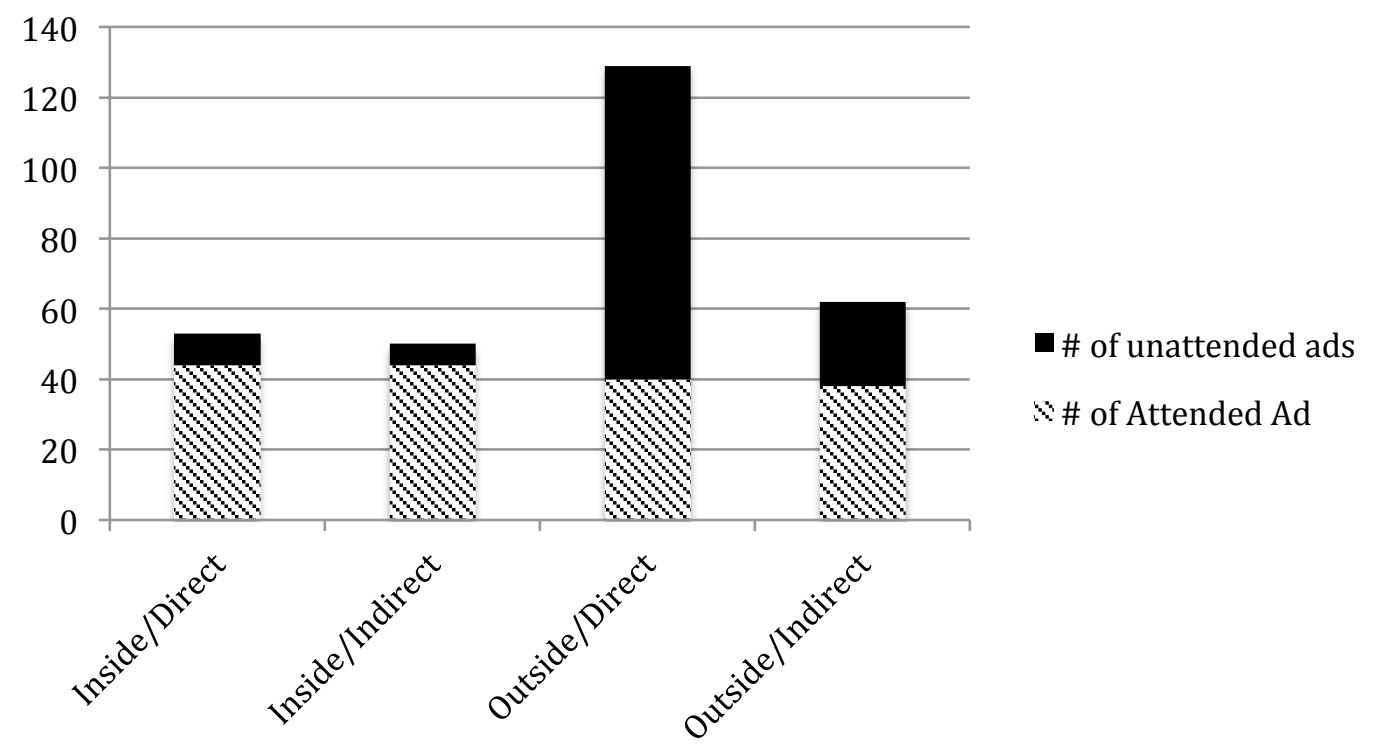

Figure 5.1: Attention rate

\section{Advertising Evaluation}

One hundred and twenty-eight subjects who did not pay attention to SNS ads were excluded from hypothesis testing. Therefore, only 166 out of 294 participants were 
included. To test the hypotheses, a 2 (inside timeline vs. outside timeline) x 2 (direct path vs. indirect path) ANOVAs was conducted for the three dependent variables (Aad, Ab, and PI). Results are discussed below.

\section{Attitude Toward the Advertisement}

Hypotheses 1a and 2a predicted the interaction effect of ad location and ad path in SNSs on consumers' attitude towards the advertisement. To test hypotheses, a $2 \times 2$ ANOVA was performed on Aad. As suggested in the ANOVA table 5.3, two main effects (ad location and ad path) were shown to be not significant $\left(\mathrm{F}_{\text {ad location }}(1,163)=.60, \mathrm{p}\right.$ $\left.>.05 ; \mathrm{F}_{\text {ad path }}(1,163)=1.62, \mathrm{p}>.05\right)$. However, results show that there is a statistically significant interaction between ad location and ad path on Aad in the SNS environment as shown in table $5.3(\mathrm{~F}=6.76, \mathrm{P}<.05)$.

Subjects exposed to the ad located inside the user's timeline reported more positive attitude towards the ad when it was sent via the indirect path $(\mathrm{M}=4.62)$ rather than the direct path $(\mathrm{M}=3.93)$. On the other hand, subjects showed more favorable attitude toward the ad when the ad is delivered by direct path $(\mathrm{M}=4.35)$ than the indirect path $(\mathrm{M}=4.32)$ in the outside ad condition as shown in table 5.4. Therefore, Hypothesis 1a and $2 \mathrm{a}$ are supported.

\section{Attitude toward the Brand}

Hypothesis $1 \mathrm{~b}$ and $2 \mathrm{~b}$ predicted the interaction effect of ad location and ad path in SNSs on consumers' attitude towards the brand. Again, to test hypothesis $1 \mathrm{~b}$ and $2 \mathrm{~b}, \mathrm{a} 2 \mathrm{x}$ 2 ANOVA was performed on Ab. According to the results, two main effects (ad location and ad path $)$ are not statistically significant $\left(\mathrm{F}_{\text {ad location }}(1,163)=.80, \mathrm{p}>.05 ; \mathrm{F}_{\text {ad path }}(1\right.$, 
$163)=.48, \mathrm{p}>.05)$. However, results indicate that there is a statistically significant interaction between ad location and ad path on Ab in the SNS environment as shown in Table 1(F=4.51, $\mathrm{P}<.05)$. (See table 5.3)

Subjects exposed to the ad located inside the user's timeline reported more positive attitude towards the brand when it was sent via the indirect path $(\mathrm{M}=4.57)$ rather than the direct path $(\mathrm{M}=4.22)$. On the other hand, subjects showed more favorable attitude toward the brand when the ad is delivered by direct path $(\mathrm{M}=4.49)$ than the indirect path $(\mathrm{M}=4.21)$ in the outside ad condition as shown in table 5.4. Therefore, Hypothesis $1 \mathrm{~b}$ and $2 \mathrm{~b}$ are supported.

\section{Purchase Intention}

To test hypothesis $1 \mathrm{c}$ and 2c, a 2 × 2 ANOVA was performed on PI. The ANOVA results discovered no main effects $\left(\mathrm{F}_{\text {ad location }}(1,163)=1.44, \mathrm{p}>.05 ; \mathrm{F}\right.$ ad path $(1,163)$ $=.56, \mathrm{p}>.05)$. However, results show that there is a statistically significant interaction between ad location and ad path on PI in the SNS environment as shown in table 5.3(F = $4.95, \mathrm{P}<.05)$.

Subjects exposed to the ad located inside the user's timeline reported stronger purchase intention when it was sent via the indirect path $(M=3.78)$ rather than the direct path $(M=3.18)$. On the other hand, subjects showed more positive purchase intention when the ad is delivered by direct path $(\mathrm{M}=3.35)$ than the indirect path $(\mathrm{M}=3.03)$ in the outside ad condition as shown in table 5.4. Therefore, Hypothesis $1 \mathrm{c}$ and $2 \mathrm{c}$ are also supported. 


\begin{tabular}{llll}
\hline Dependent Variables & Factor & F-value & p-value \\
\hline \multirow{3}{*}{ Attitude toward the advertisement } & Ad location & .60 & .807 \\
& Ad path & 1.62 & .205 \\
& Ad location x Ad path & 6.76 & .010 \\
\hline \multirow{3}{*}{ Attitude toward the brand } & Ad location & .80 & .778 \\
& Ad path & .48 & .826 \\
& Ad location x Ad path & 4.51 & .035 \\
\hline \multirow{3}{*}{ Purchase Intention } & Ad location & 1.44 & .232 \\
& Ad path & .56 & .455 \\
& Ad location x Ad path & 4.95 & .027 \\
\hline
\end{tabular}

Table 5.3: Univariate Analysis of Variance Results

\begin{tabular}{|c|c|c|c|c|c|}
\hline \multirow[t]{2}{*}{ Dependent Variables } & \multicolumn{2}{|c|}{ Independent Variables } & \multirow[b]{2}{*}{$\mathbf{M}$} & \multirow[b]{2}{*}{ SE } & \multirow[b]{2}{*}{$n$} \\
\hline & Ad location & Ad path & & & \\
\hline \multirow{4}{*}{$\begin{array}{l}\text { Attitude toward the } \\
\text { advertisement }\end{array}$} & Inside & Direct & 3.93 & 1.40 & 44 \\
\hline & & Indirect & 4.62 & .95 & 44 \\
\hline & Outside & Direct & 4.35 & .96 & 40 \\
\hline & & Indirect & 4.11 & 1.27 & 38 \\
\hline \multirow{4}{*}{ Attitude toward the Brand } & Inside & Direct & 4.22 & 1.04 & 44 \\
\hline & & Indirect & 4.57 & .82 & 44 \\
\hline & Outside & Direct & 4.50 & .87 & 40 \\
\hline & & Indirect & 4.21 & 1.03 & 38 \\
\hline \multirow{4}{*}{ Purchase Intention } & Inside & Direct & 3.13 & 1.35 & 44 \\
\hline & & Indirect & 3.78 & 1.39 & 44 \\
\hline & Outside & Direct & 3.35 & 1.40 & 40 \\
\hline & & Indirect & 3.03 & 1.49 & 38 \\
\hline
\end{tabular}

5.4: Cell Means and Sample Sizes 


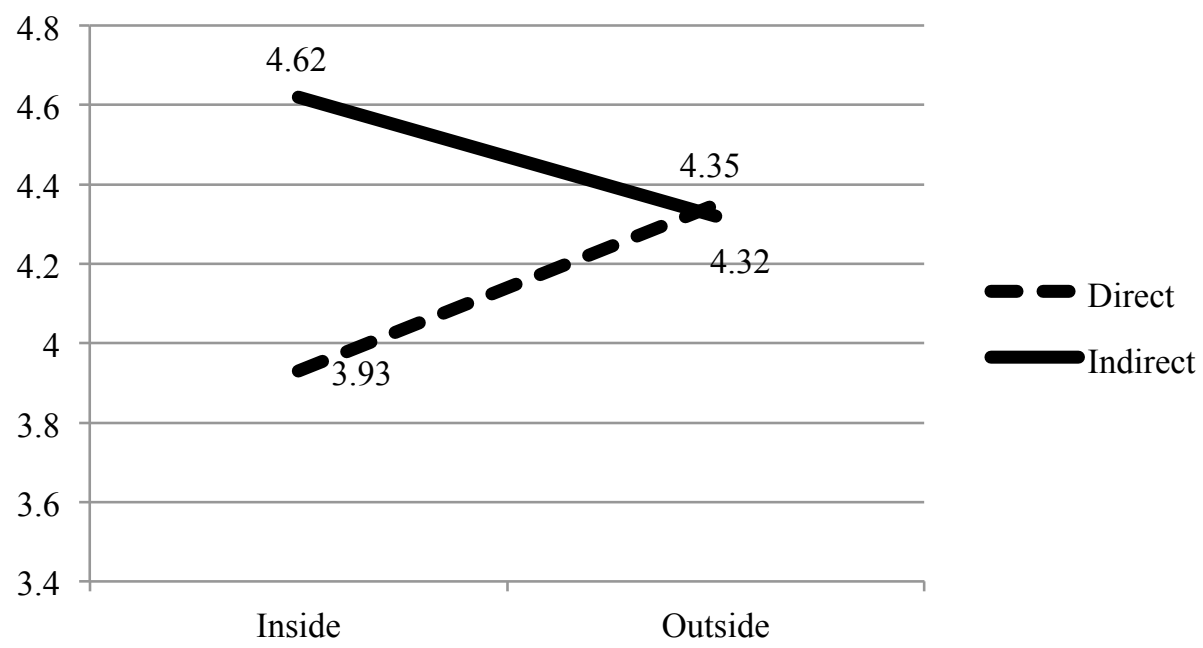

Figure 5.2: Mean attitude toward the advertisement by ad location and ad path

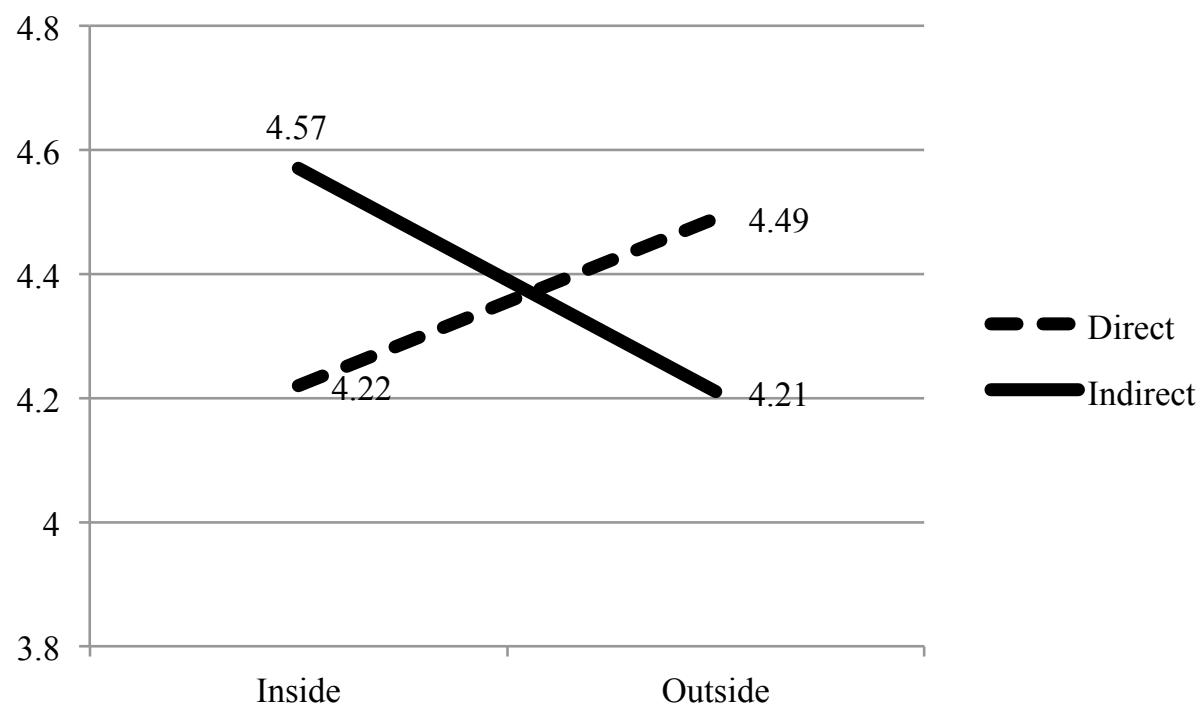

Figure 5.3: Mean attitude toward the brand by ad location and ad path 


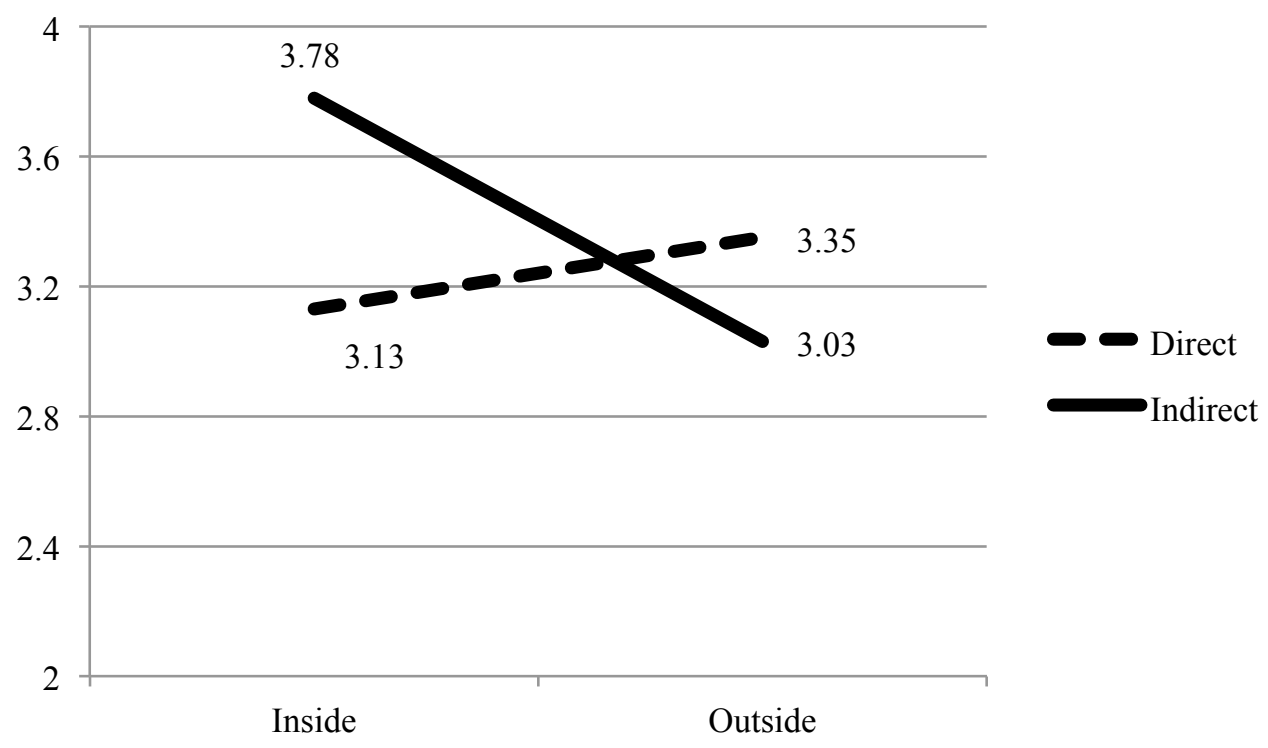

Figure 5.4: Mean purchase intention by ad location and ad path 


\section{CHAPTER 6: DISCUSSION AND CONCLUSION}

\section{DISCUSSION}

As the populations attached to SNSs prepare to exceed a billion, marketers have flocked to SNSs as a promising advertising platform. Nevertheless, concerns have persisted about effective ways to advertise on SNSs. For example, even as this study was conducted, Facebook introduced a new visual look of its news feed making it larger and offering video; they also split up the news feed into several subcategories. This effort was not only to create greater engagement with users, but also to provide more effective ads. In spite of the continuous growth in ad spending and improvements on SNSs, CTR for SNS ads are much lower than those from other forms of online ads. Further, consumers' inattention to SNS ads has been found to be prominent.

Therefore, this research was designed to explain the mechanism behind consumers' reaction to SNS ads. Based on PKM, this research first examined in a pretest how two major characteristic of SNS ads (ad location and ad path) contribute to consumers' ad identification. As expected, it was verified that ad location and ad path influences the level of ad perception in the pretest. As a result, if an ad is located inside the news feed, ads from brands were more likely to be perceived as an ad than had they come via the indirect path. The reverse was true for ads located outside the timeline. This study assumed that a high level of ad identification is more likely to lead to the arousal of an automatic defensive mechanism and thus examined the interaction effect of ad location and ad path on inattention to SNS ads, and subsequent response to attended ads.

Findings from the study show that attention to SNS ads is impacted according to 
ad location and path. The level of attention to SNS ads is ordered as follows:

inside/indirect ad, inside/direct ad, outside/indirect ad, outside/direct ad. The level of attention for outside/direct ad was noticeably lower than any other condition.

This research then examined consumers' subsequent responses to attended ads.

When an advertisement was located inside the timeline, consumers' responses to inside/direct path were more negative than they were to the inside/indirect path. As shown in the pretest, this is because consumers can easily identify inside/direct ad as advertising; in the inside/indirect condition, consumers can easily get confused in their ad identification process. Since the timeline is where users originally communicate with people, consumers might have difficulty in classifying it as advertising or the general sharing of posts.

On the other hand, when an ad appears outside the timeline, consumers are less likely to show favorable attitude toward outside/indirect ad than outside/direct ad. In the case of an outside advertisement, people are likely to perceive both direct and indirect ads as a non-personal posting since people learn over time that they communicate with others only in their timelines. Therefore, any posting outside their timelines may easily awaken their suspicions. Especially, since they never communicate with known others outside their timeline, they might automatically feel that marketers take advantage of their relationship as a marketing tactic. This might be why consumers react more negatively to outside/indirect ads than outside/direct ads.

Overall, the results from this study verify the persuasion knowledge model (Friestand and Wright 1994) as a mechanism behind consumers' responses to SNS ads. 
The current study illustrates that ad location and ad path are significant influencers on consumers' reactions towards SNS ads. Moreover, the results evidenced that an interaction of ad location and ad path varies the level of tactic perception. Tactic perception automatically activates persuasion knowledge and defense mechanisms, consequently affecting consumers' attention to SNS ads and responses.

\section{THEORETICAL CONTRIBUTION}

This study yields several theoretical contributions. The chief of which is that, by adapting persuasion knowledge model, it deepens the understanding of consumers' inattention to SNS ads and their subsequent responses to it. In spite of the significant increase in the amount of SNS ads, there has been little research on them. Kelly, Kerr, and Drennan (2010) did examine the predictors of advertising avoidance on social networking sites (SNSs), though their subjects were limited to teenagers. Therefore, this research extends the theoretical discussion on the mechanism behind consumers' defensive reaction to SNS ads.

Another noteworthy contribution the extending of the discussion of persuasion knowledge in SNSs. The study highlights the importance of ad location and ad path in the ad identification process, which leads to automatic activation of persuasion knowledge. Since persuasion knowledge remains dormant until stimulated, what triggers tactic perception and persuasion knowledge are important components. Few studies, however, have examined the factors promoting the activation of persuasion knowledge. Campbell and Kirmani (2000) found as a predictor the target's cognitive ability. Kirmani and Zhu (2007) argued that regulatory focus affects consumers' awareness of a persuasion attempt 
as a tactic. Since these factors are personal traits rather than situational traits, marketers might have no control over them. However, this research holds up two situational factors (ad location and ad path) that marketers can manipulate. Therefore, our discussion about the impact of ad location and ad path not only uncovers the predictors for tactic perception, but also provides insights for marketers.

The current study's methodology of is in two ways differentiated from other research. First, since most online advertising research has assumed that consumers attend to online advertisements, researchers have commonly focused on what occurs after users have paid attention to an ad. However, by paying attention to the prominent ad avoidance phenomenon in SNSs, this research analyzes consumers' responses in two steps. First, it examined consumers' attention to each condition, knowing which is the advertisers' first task. Then, after excluding the subjects not paying attention to SNS ads, we tested the subsequent responses of those remaining to SNS ads, the advertisers' follow-up task. SNSs are very private online spaces, making them difficult arenas in which to conduct experiments. This research, though, conducts experiment by creating a fictional SNS environment, but one that subjects reported as having a high level of similarity with their own SNSs. Therefore, this research provides methodological guidelines to whoever is interested in conducting research on SNSs.

In sum, this study, by adapting persuasion knowledge model, not only demonstrates the mechanism behind consumers' responses to SNS ads but also provides a more elaborate methodology for research on SNSs. 


\section{MANAGERIAL IMPLICATION}

The current study is one of the first endeavors to examine what drives consumers' defensive reactions to SNS ads. As such, it is expected to provide several practical insights both for social media advertisers.

Findings from this study propose that consumers' ad identification (tactic perception) plays a significant role in determining consumers' coping behavior. When consumers identify certain contents as advertising, they behave in a more defensive way (e.g., inattention, negative attitude toward the ad), so advertisers need to consider how they could embed advertising in social media contexts so as to be more difficult to categorize.

As evidenced by the results, advertisers need to decide where to place ads and how to deliver them to improve their effects. Specifically, if advertisers place their advertisement inside users' timelines, they might achieve high levels of ad exposure to their target consumers. However, they must keep in mind that the after-effect could differ remarkably according to who sends the message. Consumers are likely to prefer ads sent indirectly by their friends than those sent directly by a specific brand. Advertisers need to then clarify what their goal is (mere exposure vs. favorable after-effect towards ads) and then set the ad path.

On the other hand, if advertisers place their advertisements outside users' timelines, advertisers should be aware of the fact that consumers are likely to either quickly withdraw their attention or totally miss it. Interestingly, once advertisers succeed in attracting consumers' attention, the after-effect of SNS ads is more positive with 
outside/direct ads than with outside/indirect ads. Therefore, when advertisers place their ads outside timelines, it might be a better strategy for them to send out advertisements under a brand name and use an attention-grabbing strategy (e.g., animation effects).

In this way, this research is able to suggest practical ad strategies to marketers suffering from consumer skepticism and ad avoidance.

\section{LIMITATION AND FUTURE RESEARCH}

As with all empirical investigations, the current research has some limitations that would suggest needs for future research. In this study, consumers' attention to SNS ads was measured by adapting the concept of recognition (Hsieh and Chen 2011), which might not be able to capture consumers' actual eye movement and fixation. Thus, further research should be conducted using various methods such as physiological measures (e.g., eye tracking) to deepen the understanding consumer response to SNS ads. Further, only one product category (e.g., coffee) and one social networking platform (e.g., Facebook) were used in this study. Although the chosen product category and platform were based on consumers' general SNSs usage patterns, results from the study might not have the needed generalizability. Future research would need to vary product categories and platforms.

Another limitation is the use of a fictitious Facebook page. Even though it created a quasi-Facebook page that subjects felt held high levels of similarity with an authentic one, this fictitious page might constrain subjects from engaging with information as they would on their own Facebook page. However, there exist so many uncontrollable exogenous factors had the researcher used a real SNS, this methodology, we believe, 
outweighs any validity concern.

SNSs today are more diverse, reflecting consumers' various needs and wants. For example, LinkedIn is known as a "professional network," whereas Twitter describes itself as an "information network." On the Internet, information-seekers are more focused on the task at hand than entertainment seekers (Rodgers and Sheldon, 1999; Li and Bucovak 1999). Therefore, information seekers might have smaller cognitive capacity for advertisements than entertainment seekers (Rodgers and Sheldon, 1999; Li and Bucovak 1999). Given this, future research should consider diverse forms of SNSs to create more comprehensive theoretical models to explain consumers' responses to SNS ads. Finally, another limitation is the use of a fictitious Facebook page. Subjects might have felt the navigation to be less than realistic. Therefore, if replicated in more realistic setting, the results should better explain the effect of ad location and ad path on consumers' responses to SNS ads. 


\section{Appendix: Stimulus for Main Study}

\section{(1) Inside/Indirect ad}

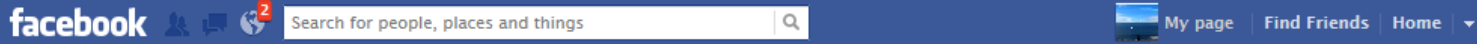

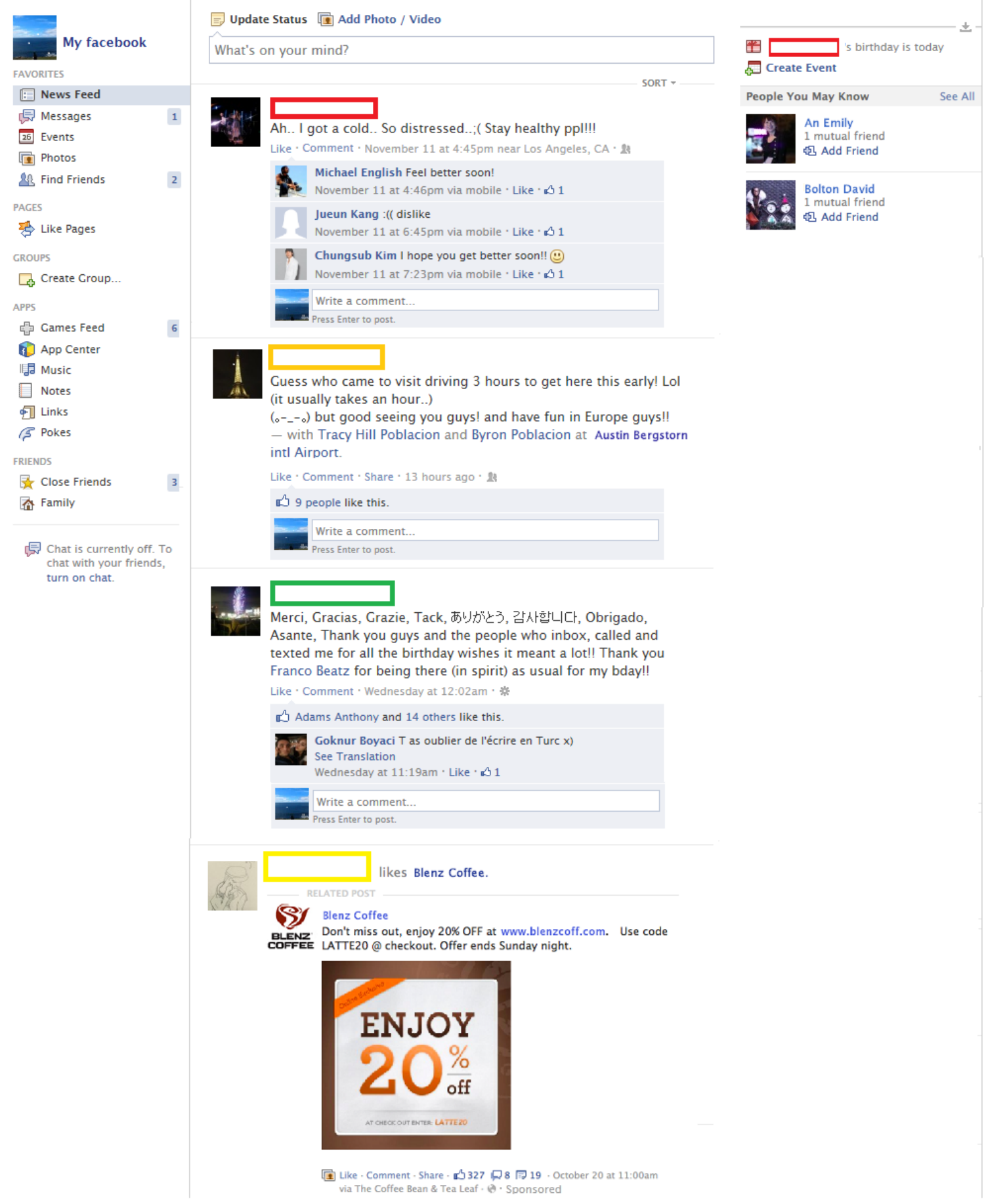




\section{(2) Outside/Indirect Ad}

facebook \& 난 $\theta^{2}$ Search for people, places and things

曰 Update Status 国 Add Photo / Video

My facebook

FAVORITES

[: News Feed

谓 Messages

226 Events

[- Photos

\&3 Find Friends

PAGES

Like Pages

GROUPS

$\square$ Create Croup...

APPS

Cames Feed

b. App Center

喟 Music

Notes

क्ञ Links

is Pokes

FRIENDS

展 Close Friends 3

通 Family

织 Chat is currently off. To chat with your friends, turn on chat. intl Airport.

C 9 people like this.

Write a comment

- Press Enter to post.
What's on your mind? SORT -

6

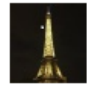

Ah.. I got a cold.. So distressed..;( Stay healthy ppl!!!

Like · Comment - November 11 at 4:45 pm near Los Angeles, CA · 8

A. Michael English Feel better soon!

2

nobile · Like ' 1

Jueun Kang :( dislike

November 11 at $6: 45 \mathrm{pm}$ via mobile - Like · 1

(7) Chungsub Kim I hope you get better soon!! (:)

November 11 at $7: 23 \mathrm{pm}$ via mobile · Like · 1

Write a comment.

\section{(a)}

Guess who came to visit driving 3 hours to get here this early! Lol (it usually takes an hour..)

$\left({ }^{-}---\right.$o) but good seeing you guys! and have fun in Europe guys!!

- with Tracy Hill Poblacion and Byron Poblacion at Austin Bergstorn

Like ' Comment ' Share $\cdot 13$ hours ago $\cdot 2 s$

Merci, Gracias, G

Merci, Gracias, Grazie, Tack, ありがとう, 감사합니다, Obrigado,

Asante, Thank you guys and the people who inbox, called and texted me for all the birthday wishes it meant a lot!! Thank you Franco Beatz for being there (in spirit) as usual for my bday!!

Like ' Comment ' Wednes day at 12:02am ' * *

Ad Adams Anthony and 14 others like this.

7. Goknur Boyaci $T$ as oublier de l'écrire en Turc $x$ See Translation

Wednesday at 11:19am · Like $\cdot ß 1$

Write a comment.

4..2. Press Enter to post.
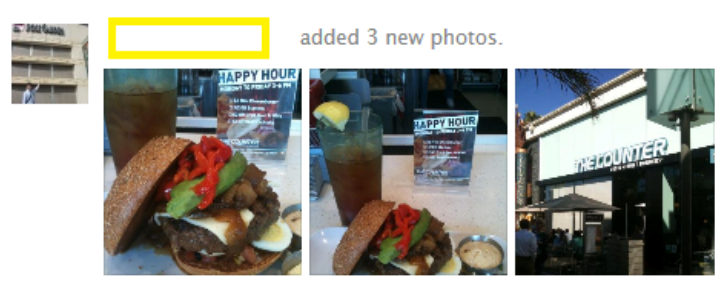

9 hours ago via mobile $\cdot$ 当

My page Find Friends Home

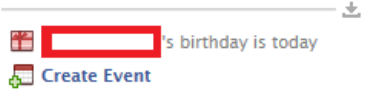

People You May Know

See All

An Emily

1 mutual friend

Th: 1 mutual friend

1 mutual friend

Sponsored 에

See All

1

ikes Blenz Coffee. RELATED POST

(3) Blenz Coffee

最e Don't miss out. enjoy 20\% OFF at www.blenzcoff.com. Use code LATTE20 @ checkout Offer ends Sunday night.

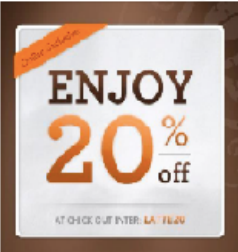

[1] Like - Commen: - Share

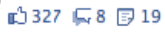
October $2 \mathrm{C}$ at 11:00am Va. Dlenz Coffee 


\section{(3) Inside/ Direct Ad}

facebook \&s $\Theta^{2}$ Search for people, places and things $Q$ a

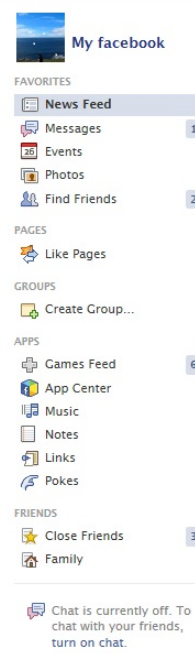

U Update Status 橉 Add Photo / Video

What's on your mind?

電

Ah.. I got a cold.. So distressed.,; (Stay healthy ppl!!!!

2

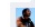

Michael English Feel better soon!

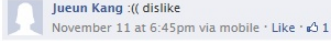

Chungsub Kim I hope you get better soon!! (1) November 11 at $7: 23 \mathrm{pm}$ via mobile $\cdot$ Like ' $\mathrm{k}$ S Write a comment

1

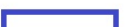

Cuess who came to visit driving 3 hours to get here this early! Lol (it usually takes an hour..)

(--o) but good seeing you guys! and have fun in Europe guys!! - with Tracy Hill Poblacion and Byron Poblacion at Austin Bergstorn

intl Airport.

tike " Comment' Share' 13 hours ago' is

هo 9 people like this.

Write a comment

12

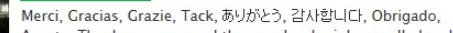
Asante, Thank you guys and the people who inbox, called and texted me for all the birthday wishes it meant a lot!l Thank you Franco Beatz for being there (in spirit) as usual for my bday!!

Like ' Comment ' Wednesday at 12:02am ' * *

Adams Anthony and 14 others like this.

20. Goknur Boyaci Tas oublier de lécrire en Turc $x$ )

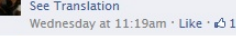

Write a commen

(S) Blenz Coffee 'Suggested Post L Like Page BLENZ Don't miss out, enjoy 20\% OFF at www.blenzcot.

\section{ENJOY 2. $\frac{\%}{\%}$

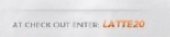

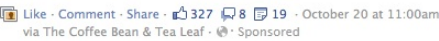

October 16 near Austin via mobile 24

Like other Tue afternoon, I feel emptiness. Nothing bad...
just calm, silence \& coldness even no emotion for good \& bad. Crystal clear emptiness. ou guys! and have fun in Europe guys!! VI Like ' Comment 'Share

(1) 17 people like this.

T) Hongmin Ahn So do I!

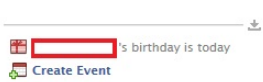

Dreate Event

52 An Emily

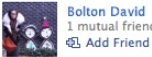




\section{(4) Outside/ Direct Ad}

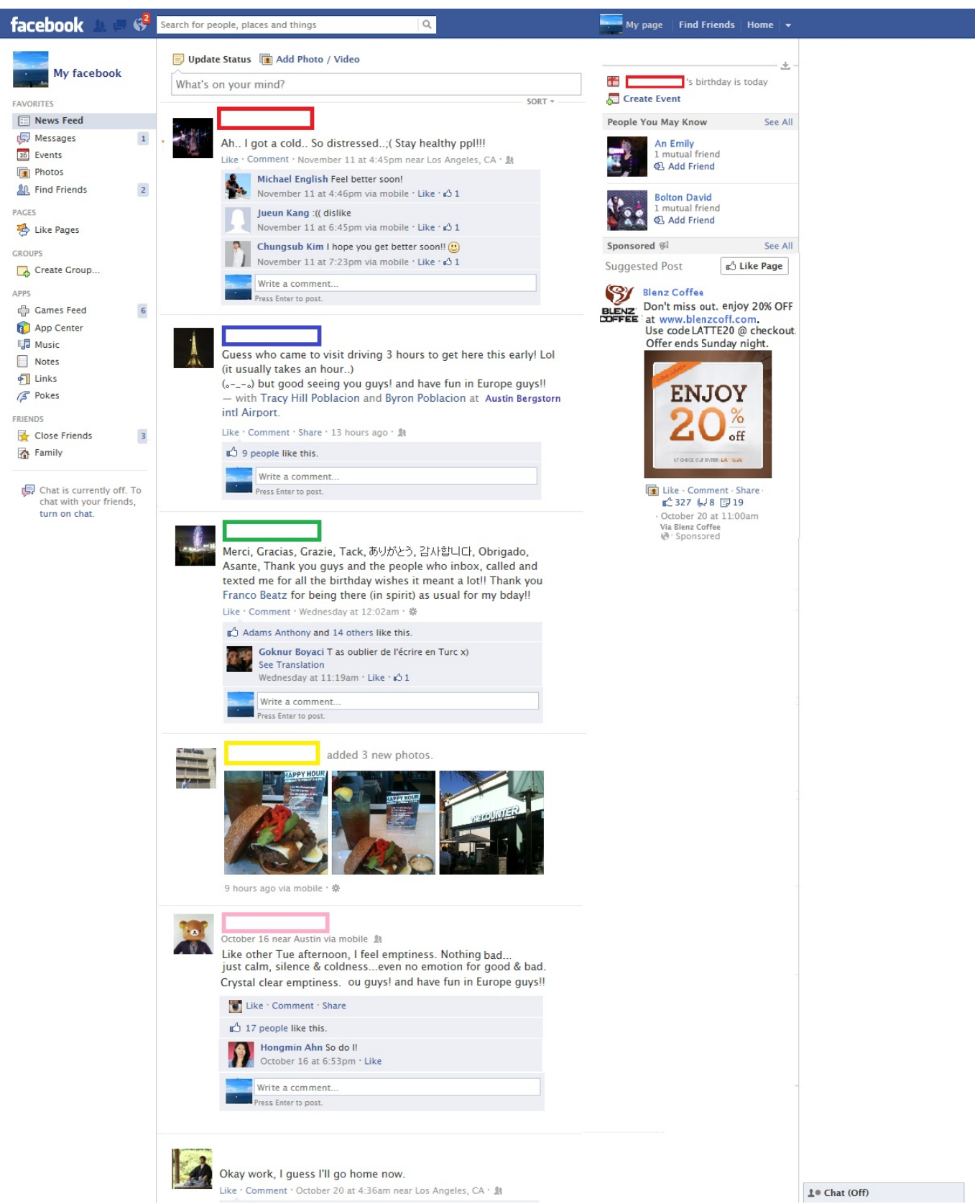




\section{REFERENCES}

A Double Click Report (2009), “2009 Year-in-Review Benchmarks,” Google http://static.googleusercontent.com/external_content/untrusted_dlcp/www.google. $\mathrm{com} / \mathrm{ko} / \mathrm{us} /$ doubleclick/pdfs/DoubleClick-07-2010-DoubleClick-BenchmarksReport-2009-Year-in-Review-US.pdf

Abernethy, Avery M. (1999), "Differences Between Advertising and Program Exposure for Car Radio Listening," Journal of Advertising Research, 31, 33-42.

AdWeek (2013), “Facebook Testing Suggested Page Ads in News Feed," Retrieved from http://www.adweek.com/news/technology/facebook-testing-suggested-page-adsnews-feed-147008

Agarwal, Ashish, Kartik Hosanagar, Michael D. Smith (2011), "Location, Location, Location: An Analysis of Profitability of Position in Online Advertising Markets," Journal of Marketing Research," 48 (6), 1057-1073.

Balasubramanian, Siva K., James A. Karrh, and Hemant Patwardhan (2006),” Audience Response to Product Placement: An Integrative Framework and Future Research Agenda. Journal of Advertising," 35(3), 115-141.

Benway, Jan P (1999), "Banner Blindness: What searching Users Notice and Do Not Notice on the World Wide Web," Ph. D dissertation, Rice University.

Bettman, James R., Mary F. Luce, and John W. Payne (1998), "Constructive Consumer Choice Processes," Journal of Consumer Research, 25 (3), 187-217.

Boyd, Danah M. and Nicole B. Ellison (2007), "Social Network Sites: Definition, History and Scholarship," Journal of Computer-Mediated Communication, 13(1), 210230 .

Campbell, Margaret C. (1995)," When Attention-Getting Advertising Tactics Elicit Consumer Inferences of Manipulative Intent: The Importance of Balancing Benefits and Investment," Journal of Consumer Psychology, 4(3), 225-254.

Campbell, Margaret C. and Amna Kirmani. (2000), “Consumer's Use of Persuasion Knowledge: The effect of Accessibility and Cognitive Capacity on Perception of and Influence Agent. Journal of Consumer Research,” 27, 69-83.

Cannon, H., Richardson, T. and Yaprak, A. (1998), "Toward a framework for evaluating Internet Advertising effectiveness," Paper presented at the 1998 Conference of the American Academy of Advertising, Lexington, KY. 
Canzer, Brahm (2006), "E-business :Strategic Thinking and Practice," Houghton Miffin Company, Coston-New York.

Chang, Pao-long and Ming-Hua Chieng (2006), "Building Consumer-Brand Relationship: A Cross-Cultural Experiential View," Psychology \& Marketing, 23(11), 927-959.

Chen, Qimei and Wells Williams D. (2000) "A New Look at Traditional Measures: Attitude toward the Site," Paper presented at the 2000 Conference of the American Academy of Advertising.

Cho, Chang-Hoan (1999), "How Advertising Works on the WWW: Modified Elaboration Model, Journal of Current Issues \& Research in Advertising,” 21(1), 34-50.

Cho, Chang-Hoan and Hongsick J. Cheon (2004), "Why Do People Avoid Advertising on the Internet?" Journal of Advertising, 33(4), 89-99.

CNNMoney (2012), “GM to stop advertising on Facebook," Retrieved March 25, 2013, from http://money.cnn.com/2012/05/15/autos/gm_facebook/index.htm

Cox, Carmen (2011), "Facebook to Show Sponsored Ads in News Feed in 2012," ABC News (Dec 21) Retrieved from http://abcnews.go.com/Technology/facebook-put-sponsored-adstimeline-newsfeed-january-2012/story?id=15205346\#.UVX7RqlgOFI

Cronlin, John J. and Nancy E. Menelly (1992), "Discrimination vs. Avoidance: Zipping of Television Commercials. Journal of Advertiisng," 21(2), June, 1-7.

Dahlen, Micael and Mats Edenius (2007), "When is advertising advertising? Journal of Current Issuse and Research in Advertising," 29 (1), 33-42.

Dannahor, Peter J. (1995), "What happens to Television Ratings During Commercial Breaks?" Journal of Advertising Research, 35 (March), 37-48.

Dix, Stephen and Ian Phau (2008), "Revisiting the Blurring Practices Between Editorials and Adveritisng," Paper presented at the 2008 Australian \& New Zealand Marketing Academy Conference.

Donthu, Naveen, Joseph Cherian. and Mukesh Bhargava (1993), "Factors Influencing Recall of Outdoor Advertising," Journal of Advertising Research, 33(May/June), 64-72.

Dreze, Xavier and François-Xavier Hyssherr (2003), "Internet Advertising: Is Anybody Watching?" Journal of Interactive Marketing, 17(4), 8-23. 
Duff, Brittany, R. L. and Roald J. Faber (2011), "Missing the Mark: Advertising Avoidance and Distractor Devaluation," The Journal of Advertising, 40(2), summer, 51-62.

Edwards, Steven M., Hairong Li. and Joo-hyun Lee (2002), "Forced Exposure and Psychological Reactance: Antecedents and Consequences of the Perceived Intrusiveness of Pop-up Ads, ” Journal of Advertising, 31(3), 83-95.

eMarketers (2011), "Social Network Ad Revenues to Reach \$10 Billion Worldwide in 2013," (Oct 5) http://www.emarketer.com/Article/Social-Network-Ad-RevenuesReach-10-Billion-Worldwide-2013/1008625.

eMarketers (2012), "Total Worldwide Social Network Ad Revenues Continue Strong Growth," eMarketer (Feb 24), http://www.emarketer.com/Article/TotalWorldwide-Social-Network-Ad-Revenues-Continue-Strong-Growth/1008862.

Enders, Albrecht, Harald Hungenberg, Hans-Peter Denker and Sebastian Mauch (2008), "The Long Tail of Social Networking. Revenue Models of Social Networking Sites," European Management Journal, 26, 199-211.

Ferguson, Douglas A., Elizabath M. and Perse, E, M. (1993), "Media and Audience Influences on Channel Repertoire," Journal of Broadcasting \& Electronic Media, $37(1), 31-47$.

Forbes (2012), “Online Ad Spending Tops \$100 Billion in 2012,” Retrieved from http://www.forbes.com/sites/roberthof/2013/01/09/online-ad-spending-tops-100billion-in-2012/

Frank, Betsy (1984)," Television: And Now a Word From our Zap," Marketing \& Media Decisions, 19, 162-166.

Friestad, Marian and Peter Wright (1994), "The Persuasion Knowledge Model: How Peo ple Cope With Persuasion Attempts, ” Journal of Consumer Research, 21(1), 1-31.

Goodstein, Ronald C.(1993), "Category-based Applications and Extensions in Advertising: Motivating More Extensive Ad Processing, "Journal of Consumer Research, 20(June), 87-97.

Greene, William F. (1988), "Maybe the Valley of the Shadow isn't so Dark After All. Journal of Advertising Research," 28(5), 11-15.

Ha, Loulsa (2008), "Online Advertising Research in Advertising Journals: Review. Journal of Current Issues and Research in Advertising," 30 (spring), 31-48. 
Ha, Loulsa and McCann Kim (2008), “An Integrated Model of Adertising Clutter in Offline and Online Media," International Journal of Advertising, 27(4), 569-592.

Haley, Russell I. and Peter B. Case (1979), "Testing Thirteen Attitude Scales for Agreement and Brand Discrimination," Journal of Marketing, 43(4) (Autumn), 20-32.

Clary, Gil E., Robert D. Ridge, Arthur A. Stukas, Mark Snyder, John Copeland, Julie Haugen, and Peter Miene (1998), "Understanding and Assessing the Motivations of Volunteers: A Functional Approach," Journal of Personality and Social Psychology, 74(6), 1516-1530.

Heeter, Carrie and Cohen, E. (1988)," Viewing Style Differences Between Radio and Television," pp 113-122, Carrie Hetter and Bradley S. Greenberg (eds.), Norwood, NJ: Ablex Publishing.

Heteter, Carrie and Bradly S. Greenberg, (1985), "Profiling the Zappers. Journal of Advertising Research," 25, 15-19.

Hsieh, Yu-Chen and Kuo-Hsiang Chen (2011), "How different information types affect viewer's attention on internet advertising," Computers in Human Behavior, 27 (2), 935-945.

IDC (2008), "Consumer Attitudes About Advertising and the Implications for Advertising on Social Networks," Retried from http://www.slideshare.net/cdangson/socialadvertising-research.

Jothi, Sri P., M. Neelamalar, \& Prasad R. Shakthi, (2011), “Analysis of Social NetworkignSites: A study on Effective Communication Strategy in Developing Brand Communication," Journal of Media and Communication Studies, 3(7), 234-242.

Kahneman, D. and Henik, A. (1981), "Perceptual Organization and Attention," pp.181211, in M. Kubovy \& J. r. Pomerantz (Eds). Perceptual Organization, Hillsdale, N.J:Erlbaum.

Kaplan, Andreas M. and Michael Haenlein (2010), "Users of the world, unite! The challenges and opportunities of social media," Business Horizons, 53 (1), 59-68.

Katz, Elihu, Jay G. Blumler and Michael Gurevitch, (1973-1974), "Uses and Gratification Research," The Public Opinion Quarterly, 37(4), 509-523.

Kelly, Louise, Gayle Kerr and Judy Drennan (2010), "Avoidance of Advertising in Social Networking Sites: The Teenage Perspective," The Journal of Interactive Advertising, 10 (2), 16-27. 
Kern, Eliza (2012), "Surprise! Twitter study shows that promoted tweets result in sales," GIGaom, (Nov 20), Retrieved from http:/gigaom.com/2012/11/20/surprise-twitte r-study-shows-that-promoted-tweets-result-in-sales/

Kim, Dolye, Anastasia Minor and Carolyn Weyrich (1997)," Banner Ad Location Effectiveness Study," Webreference (May 21) http://www.webreference.com/dev/banners/index.html

Kirmani, Amna, and Rui Z. Zhu (2007), "Vigilant Against Manipulation : The effect of Regulatory Focus on the Use of Persuasion Knowledge" Journal of Marketing Research, 44(Nov), 688-701.

Korgaonkar, Pradeep K. and Lori D. Wolin (1999), “A Multivariate Analysis of Web Usage," Journal of Advertising Research, (March/April), 53-68.

Krugman, Dean M., Glen T. Cameron, and Candacy M.White, (1995), "Visual attention to programming and commercials: The use of in-home Observations," Journal of Advertising, 24(1), 1-12.

Lal, Ruhi and C. P. Rashmi, (2011), "An analysis on Online Advertorials and New Emerging Trends, International Journal of Management Research and Review, $1(2), 42-49$.

Lang, Annie (2000), “The Limited Capacity Model of Mediated Message Processing, Journal of Communication," 50(March), 46-70.

Lee, Angela Y. and Jennifer L. Aaker (2004), "Bringing the Frame Into Focus: The of Regulatory Fit on Processing Fluency and Persuasion," Journal of Personality and Social Psychology, 86 (2), 205-218.

Li, Hairong. and Janice L. Bukovac (1999), "Cognitive Impact of Banner ad Characteristics :An Experimental Study,” J\&MC Quarterly, 75(2), 341-353.

Lin, Ya-Li and Ya-Wen Chen (2009), "Effects of Ad Types, Positions, Animation Lengths, and Exposure Times on the Click-Through Rate of Animated Online Advertising," Computers \& Industrial Engineering, 57, 580-591.

Liu, Yuping and L. J. Shrum (2001), "What is Interactivity and Is It Always such a Good Thing? Implications of Definition, Person and Situation for the Influence of Interactivity on Advertising Effectiveness," Journal of Advertising, 31(4), 53-64.

MacKenzie, Scott B. and Richard J. Lutz (1989), “An Empirical Examination of the Structural Antecedents of Attitude toward the ad in Advertising Pretesting 
Context," The Journal of Marketing, 53(2), 48-65.

Magazine Publishers of America (1979), "Consumer Perception of Increased Advertising," Magazine Newsletter of Research, 29(May), 1-7.

Magazine Publishers of America (1991), “A study of Media Involvement,” VI, New York.

Mangold, Glynn W. and David J. Faulds (2009), "Social media: the new hybrid element of the promotion mix," Business Horizons, 52(4), 357-365.

Marketing Chart (2011), “US Online Ad Spend to Grow 23.3\% in 2012," (November 5), Retrieved from Marketing Chart website: http://www.marketingcharts.com/ direct/Internet-advertising-revenues-continue-growth-20257/

McCoy, Scott, Andrea Everard, Peter Polak and Dennis F. Galletta (2007), "The Effect of Online Advertising," Communications of The ACM, 50(3), 84-88.

Mcilrath, Mary (2009), "Children's Cognitive Processing of Internet Advertising," Ph. D dissertation, University of California Santa Barbara.

Moon, Jang Ho and Wei-Na, Lee (2012), "The impact of brand information disclosure on consumer response," Journal of Advertising and Promotion Research 1(5), 187 226.

Moriarty, Sandra E. (1991), "Explorations into the Commercial Encounter," 1991 Conference of the American Academy of Advertising, Rebecca Holman, ed., Richmond, VA: American Academy of Advertising, 215-222.

Moriarty, Sandra E. and Shu-Ling Everett (1994), "Commercial Breaks: A viewing Behavior Study," Journal of Quarterly, 71, 346-355.

Neilson Netratings (2000), “Global Internet Trends,” (May), NetRatings Inc, CA, Retrieved from http://www.nielsen-netratings.com/

Neilson Online (2009), "Neilson online provides fastest growing social networks for September 2008," Retrieved from http://www.nielsen-online.com/

Newspaper Advertising Bureau, Inc. (1973), "Quantitative and Qualitative Aspects of Daily Newspaper Reading: A National Study," New York.

Nielsen, Jakob (2000), “Designing web usability: the practice of simplicity,” Indianapolis, IN: New Riders Publishing. 
Nordfalt, Jens (2005), "Track to the Future? A Study of Individual Selection Mechanisms Preceding Ad Recognition and Their Consequences," Journal of Current Issues and Research in Advertising, 27(1), 19-29.

Papacharissi, Zizi and Alan M. Rubin (2000), "Predictors of Internet Use," Journal of Broadcasting \& Electronic Media, 44 (2), 175-196.

Pillow, Bradford H. (1991), "Children's Understanding of Biased Social Cognition," Developmental Psychology, 27 (4), July, 539-551.

Regelson, Moira, and Daniel C. Fain (2006), "Predicting click-through rate using keyword clusters," In proceedings of the Second Workship on Sponsored Search Auctions.

Robertson, Thomas, S. and Rossiter, John (1974), "Children and Commercial Persuasion : An Attribution Theory Analysis," Journal of Consumer Research, 1 (1), 13-20.

Rodgers, Shelly (2000), "Predicting Sponsorship Effects Using the Sponsorship Knowledge Inventory," Unpublished doctoral dissertation. School of Journalism, University of Missouri-Columbia.

Rodgers, Shelly and Esther Thorson (2000), "The Interactive Advertising Model : How Users Perceive and Process Online Ads. Journal of Interactive Advertising, 1(1), 42-61.

Rodgers, Shelly and Kennon M. Sheldon (1999), "The Web Motivation Inventory : A new way to characterize web users," Paper presented at 1999 Conference of the American Academy of Advertising, Albuquerque, NM.

Rojas-Mendez, Jose I. and Gary Davies (2005), "Avoiding Television Advertising: Some Explanations from Time Allocation Theory," Journal of Advertising Research, 3448.

Shin, Dong H. (2009), "The Evaluation of User Experience of the Virtual World in Relation to Extrinsic and Intrinsic Motivation," International Journal of HumanComputer Interaction, 25 (6), (August), 530-553.

Siddarth, S. and Amitava Chattopadhyay (1998), "To Zap or Not to Zap : A Study of the Determinants of Channel Switching during Commercials," Marketing Science, 17(2). 124-138.

Singh, S. N. and Dalal, N. P.(1999), "Web Homepage as Advertisements," Communications of the ACM, 42(8), 91-98. 
Speck, Paul S. and Michael T. Elliott (1997), "Predictors of Advertising Avoidance in Print and Broadcast Media," Journal of Advertising, 26(3), 61-76.

Stephens, Nancy and Mary A. Stutts (1982), "Preschooler's Ability to Distinguish Between Television Programming and Commercials," Journal of Advertising, 11(2), 16-26.

Stewart, David W. and David, H. Furse, (1986), "Effective Television Advetising: A Stud y of 1000 Commercials," Lexington Books, DC Heath and Company, Lexington, MA.

The Wall Street Journal (2012), “GM Says Facebook Ads Don't Pay off,” Retrieved from http://online.wsj.com/article/SB1000142405270230419270457740639401776446 $0 . h t m l$

Valdes-Dapena, Peter (2012), "GM to stop advertising on Facebook," CNN Money (March 15), http://money.cnn.com/2012/05/15/autos/gm_facebook/index.htm

Webtrends (2011), "Facebook Advertising Performance Benchmarks \& Insights," Retrived from http://www.slideshare.net/rmlins/facebook-advertisingperformance-benchmarks-insights.

Wilkinson, J. B., Douglas R. Hausknecht and George E. Prough (1995),” Reader Categorization of a Controversial Communication: Advertisement versus Editorial." Journal of Public Policy \& Marketing, 14(2), 245-254.

William, James L. and Arthur J. Kover(1992), “Observations: Do Overall Attitudes Toward Advertising Affect Involvement with Specific Advertisement?" Journal of Advertising Research, 32(Sep/Oct), 78-83.

Wright, P., Marian Friestad and David M. Boush (2005), “The Development of Marketplace Persuasion Knowledge in Children, Adolescents, and Young Adults," Journal of Public Policy \& Marketing, 24(2), Fall, 222-233.

Yoo, Chan Yun (2009), "The Effects of Persuasion Knowledge on Click-Through of Keyword Search Ads: Moderating Role of Search Task and Perceived Faireness," J\&MC Quarterly, 86(2), 201-218.

Zanot, E. (1984), "Public Attitude Toward Advertising: The American Express," International Journal of Advertising, 3(1), 3-15

Zeff, R. and Aronson, B (1997), “Advertising on the Internet,” New York: John Wiley \& Sons, Inc. 
Zufreyden, Fred S., James H. Pedrick and Avu Sankaralingam (1993), "Zapping and Its Impact on Brand Purchase Behavior," Journal of Advertising Research, 33 (January/ February), 58-66. 